\title{
Integrated genome-wide Alu methylation and transcriptome profiling analyses reveal novel epigenetic regulatory networks associated with autism spectrum disorder
}

Thanit Saeliw ${ }^{1}$, Chayanin Tangsuwansri', Surangrat Thongkorn' ${ }^{1}$, Weerasak Chonchaiya², Kanya Suphapeetiporn ${ }^{3,4}$, Apiwat Mutirangura ${ }^{5}$, Tewin Tencomnao ${ }^{6}$, Valerie W. $\mathrm{Hu}^{7}$ and Tewarit Sarachana ${ }^{6^{*}}$ (D)

\begin{abstract}
Background: Alu elements are a group of repetitive elements that can influence gene expression through CpG residues and transcription factor binding. Altered gene expression and methylation profiles have been reported in various tissues and cell lines from individuals with autism spectrum disorder (ASD). However, the role of Alu elements in ASD remains unclear. We thus investigated whether Alu elements are associated with altered gene expression profiles in ASD.

Methods: We obtained five blood-based gene expression profiles from the Gene Expression Omnibus database and human Alu-inserted gene lists from the TranspoGene database. Differentially expressed genes (DEGs) in ASD were identified from each study and overlapped with the human Alu-inserted genes. The biological functions and networks of Alu-inserted DEGs were then predicted by Ingenuity Pathway Analysis (IPA). A combined bisulfite restriction analysis of lymphoblastoid cell lines (LCLs) derived from 36 ASD and 20 sex- and age-matched unaffected individuals was performed to assess the global DNA methylation levels within Alu elements, and the Alu expression levels were determined by quantitative RT-PCR.

Results: In ASD blood or blood-derived cells, 320 Alu-inserted genes were reproducibly differentially expressed. Biological function and pathway analysis showed that these genes were significantly associated with neurodevelopmental disorders and neurological functions involved in ASD etiology. Interestingly, estrogen receptor and androgen signaling pathways implicated in the sex bias of ASD, as well as IL-6 signaling and neuroinflammation signaling pathways, were also highlighted. Alu methylation was not significantly different between the ASD and sex- and age-matched control groups. However, significantly altered Alu methylation patterns were observed in ASD cases sub-grouped based on Autism Diagnostic Interview-Revised scores compared with matched controls. Quantitative RT-PCR analysis of Alu expression also showed significant differences between ASD subgroups. Interestingly, Alu expression was correlated with methylation status in one phenotypic ASD subgroup.

(Continued on next page)
\end{abstract}

\footnotetext{
* Correspondence: tewarit.sa@chula.ac.th

${ }^{6}$ Age-related Inflammation and Degeneration Research Unit, Department of

Clinical Chemistry, Faculty of Allied Health Sciences, Chulalongkorn

University, 154 Soi Chula 12, Rama 1 Road, Wangmai, Pathumwan, Bangkok

10330, Thailand

Full list of author information is available at the end of the article
}

(c) The Author(s). 2018 Open Access This article is distributed under the terms of the Creative Commons Attribution 4.0 International License (http://creativecommons.org/licenses/by/4.0/), which permits unrestricted use, distribution, and reproduction in any medium, provided you give appropriate credit to the original author(s) and the source, provide a link to the Creative Commons license, and indicate if changes were made. The Creative Commons Public Domain Dedication waiver (http://creativecommons.org/publicdomain/zero/1.0/) applies to the data made available in this article, unless otherwise stated. 
(Continued from previous page)

Conclusion: Alu methylation and expression were altered in LCLs from ASD subgroups. Our findings highlight the association of Alu elements with gene dysregulation in ASD blood samples and warrant further investigation. Moreover, the classification of ASD individuals into subgroups based on phenotypes may be beneficial and could provide insights into the still unknown etiology and the underlying mechanisms of ASD.

Keywords: Autism spectrum disorder, Alu elements, Retrotransposon, DNA methylation, Epigenetic regulation, Gene expression profiles, Subgrouping, Lymphoblastoid cell lines, Sex bias, Neuroinflammation,

\section{Background}

Autism spectrum disorder (ASD) refers to a group of complex neurodevelopmental disorders that are characterized according to the Diagnostic and Statistical Manual of Mental Disorders, Fifth Edition (DSM-5) criteria by two domains: (i) behavioral impairment, including significant deficits in social interactions and communication, and (ii) restricted interests and repetitive behaviors [1]. Recent data released from the Autism and Developmental Disabilities Monitoring Network have shown a $78 \%$ increase in ASD prevalence over the past decade, and approximately 1 in 68 children in the USA have ASD [2]. This increase in ASD prevalence leads to a large economic burden, including costs for healthcare, ASD-related therapy, familycoordinated services, and special education systems [3].

A number of studies have supported the hypothesis that genetic factors are strongly associated with the etiology and susceptibility of ASD. However, abnormalities in genomic DNA are found in only $10-20 \%$ of ASD cases accumulatively, partly due to the etiological heterogeneity of ASD, which has a wide variety of different risk factors in addition to genetic factors [4]. A broad variability in clinical phenotypes of ASD individuals are thought to result from complicated interactions between genetic and environmental factors that increase ASD risk $[5,6]$. Although the concordance rate among monozygotic (MZ) twins was found to range from $60 \%$ to as high as $90 \%$, notable discordance in the ASD diagnosis within monozygotic twin pairs and significant differences in the ASD severity within ASD-concordant monozygotic twin pairs have also been observed [7, 8]. This evidence strongly suggests that environmental factors may play an important role in the etiology and/or the susceptibility of ASD.

DNA methylation is a major epigenetic regulator of gene expression and associated phenotypes. Methylation patterns in genomic DNA are generated during embryogenesis and early fetal development and are altered throughout life in response to endogenous or exogenous environmental signals. Recently, differentially methylated variants (DMVs) at specific CpG sites or differentially methylated regions (DMRs) have been investigated in ASD individuals using various types of tissues, including lymphoblastoid cell lines (LCLs) [9], whole blood [10], and brain tissue samples [11-13]. Nguyen and colleagues performed a large-scale methylation profiling analysis of LCLs derived from discordantly diagnosed (i.e., ASD and non-ASD) monozygotic twins and sibling pairs [9]. The results revealed differentially methylated genes associated with several biological functions, including gene transcription, nervous system development, and other biological mechanisms implicated in ASD. Moreover, the mRNA expression level of one ASD candidate gene (e.g., retinoic acid-related orphan receptor-alpha gene, RORA), which exhibits a differential methylation pattern in ASD, was also decreased in LCLs. Reduced RORA protein levels were also observed in the brain tissues of ASD individuals. This finding suggests that molecular changes in ASD peripheral cells may reflect at least some pathobiological conditions in the brain.

Several studies involving the gene expression profiling of blood or blood-derived cell lines from ASD and nonASD subjects reported different (but somewhat overlapping) sets of differentially expressed genes (DEGs), most likely due to the heterogeneity within the ASD population. To reduce phenotypic variability and increase statistical power, $\mathrm{Hu}$ and Steinberg defined phenotypes within ASD based on cluster analyses of Autism Diagnostic InterviewRevised (ADI-R) scores [14]. Interestingly, gene expression profiling among the LCLs of ASD subgroups also showed differential expression [15]. This result suggested that the sub-classification of ASD patients could help identify subphenotype-specific risk factors in heterogeneous ASD populations. However, most global methylation and gene expression profiling studies have focused on proteincoding regions rather than noncoding regions that include repetitive sequences.

Alu elements are a group of repetitive sequences or mobile genetic elements with copy numbers in excess of one million in the human genome, thus contributing to almost $11 \%$ of the human genome [16]. Alu elements belong to a class of retrotransposons termed SINEs (short interspersed elements). Several reports have demonstrated that Alu elements can influence gene expression via insertion into the gene structure and can attract transcription factor binding to regulate gene expression [17]. Alu elements have many CpG residues in their sequences, and these $\mathrm{CpG}$ residues are common methylation sites. Methylated CpGs represent approximately 
$23 \%$ of all methylated residues in the human genome [18]. DNA methylation can be altered by exposure to environmental factors that can reduce Alu element methylation in human tissues [19], and there is evidence that Alu methylation plays an important role in cell proliferation and resistance to DNA damage [20]. However, the role of Alu elements and their methylation in ASD remains unclear.

In this study, we therefore aimed to investigate the association between Alu elements and altered gene expression profiles in ASD. First, publicly available gene expression data from previously published ASD transcriptome profiling studies were downloaded from the GEO DataSets database. DEGs from each ASD transcriptome study were identified, and the association between the DEGs from each study and human Alu-inserted genes were determined by Fisher's exact test. Moreover, the DEGs with Alu insertion were identified and subsequently subjected to Ingenuity Pathway Analysis (IPA) to predict the biological functions, canonical pathways, and gene regulatory networks associated with ASD. A combined bisulfite restriction analysis (COBRA) of Alu was then performed to assess DNA methylation within Alu elements and associated CpGs, which might regulate the expression of Alu elements and Alu-inserted genes. The schematic diagram showing the experimental workflow of this study is illustrated in Fig. 1.

\section{Methods}

\section{Data collection}

Gene expression profiles of ASD and control individuals were obtained from the NCBI Gene Expression Omnibus database (GEO DataSets: http://www.ncbi.nlm.nih. gov/gds) using the following criteria: the included studies must be ASD studies; the studies must include blood-based gene expression profiles from microarray experiments; and the sample sizes must be greater than or equal to 40 samples. All supplementary information, including series matrix files and related platforms, was

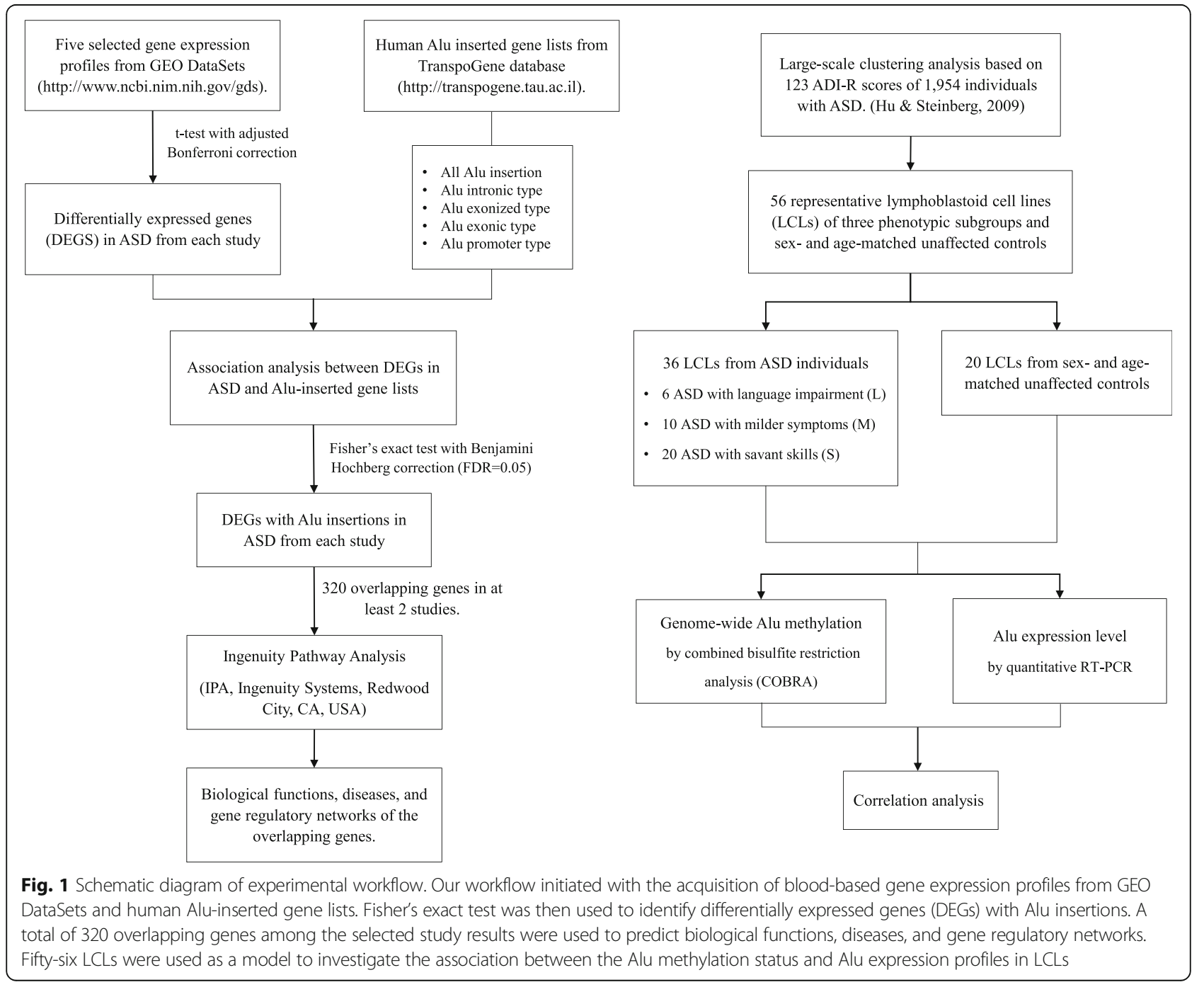


freely available in GEO DataSets [21, 22]. The details of each study are provided in Table 1.

Alu subfamily-inserted gene lists of Human Genome 18 (UCSC hg18, NCBI build 36.1) were downloaded from the TranspoGene database (http://transpogene.tau.ac.il), which is a publicly available database of transposed elements (TEs) located within protein-coding genes [23]. For the human Alu-inserted genes, a single gene can be inserted by multiple Alu elements with different insertion types. In this study, we obtained all genes with at least one instance of one of the four types of Alu insertions, namely, the exonic, exonized, intronic, and promoter inserts (Table 2). All human Alu subfamily consensus sequences were obtained from Repbase, which is a database of repetitive elements in eukaryotic genomes [24].

\section{Identification of DEGs and association with Alu-inserted genes}

The transcriptome profile from each study was analyzed separately by Multiple Experiment Viewer (MEV) [25]. All transcriptome data were filtered using a 70\% cutoff, which removes transcripts for which intensity values are missing in $>30 \%$ of the samples. The available transcripts were used for identifying DEGs in ASD with twotailed $t$ tests with adjusted Bonferroni correction. All studies obtained from GEO DataSets employed ASD samples vs. sex- and/or age-matched controls in the analyses. The DEGs and non-DEGs were intersected with the human Alu-inserted gene lists, and the number of intersected genes was classified based on a crosstab $2 \times 2$ table into four categories, namely, DEGs with Alu
Table 2 Total number of the Alu-inserted gene lists from TranspoGene database

\begin{tabular}{ll}
\hline Insertion type & Alu-inserted genes $(n)$ \\
\hline All insertion types* & 13,534 \\
Exonized type & 812 \\
Exonic type & 1593 \\
Intronic type & 13,245 \\
Promoter type & 557 \\
\hline
\end{tabular}

We obtained the lists of human genes with at least one Alu elements from the TranspoGene database. The lists can be categorized into five types of Alu insertions: exonized, exonic, intronic, promoter, and all insertion. Note that multiple Alu elements can be inserted within a single gene with different insertion types. Therefore, the total number of Alu-inserted genes is less than the sum of the exonic, exonized, intronic, and promoter types. These lists of Alu-inserted genes were used for subsequent overlap analyses with differentially expressed genes (DEGs) in ASD

*List of genes with at least one instance of one of the four types of Alu insertions

insertion, DEGs without Alu insertion, non-DEGs with Alu insertion, and non-DEGs without Alu insertion. Fisher's exact test was then used to determine whether the DEG distributions were dependent on the human Alu-inserted gene lists. Moreover, the DEGs were classified as downregulated or upregulated and used for comparison with the human Alu-inserted gene lists. These processes were repeated with each type of human Alu insertion, including intronic, exonized, exonic, and promoter type. A Fisher's exact test $P$ value with BenjaminiHochberg correction $(\mathrm{FDR}=0.05)$ of less than 0.05 was considered significant.

To identify the reproducibility of the human Aluinserted genes that were differentially expressed in

Table 1 Details of the gene expression profiles obtained from GEO DataSets

\begin{tabular}{|c|c|c|c|c|c|c|c|c|}
\hline \multirow[t]{2}{*}{ GSE DataSets } & \multirow[t]{2}{*}{ Titles } & \multirow[t]{2}{*}{ Sample type } & \multicolumn{3}{|l|}{ Sample information } & \multicolumn{2}{|c|}{ Number of transcripts } & \multirow[t]{2}{*}{ References } \\
\hline & & & Sample matching & Sample size & Total & $\begin{array}{l}\text { Cutoff filter } \\
\text { at } 70 \%\end{array}$ & $\begin{array}{l}\text { Available } \\
\text { transcripts with } \\
\text { Alu insertion }\end{array}$ & \\
\hline GSE15402 & $\begin{array}{l}\text { Gene expression profiling } \\
\text { differentiates autism case- } \\
\text { controls and phenotypic } \\
\text { variants of autism spectrum } \\
\text { disorders }\end{array}$ & $\begin{array}{l}\text { Lymphoblastoid } \\
\text { cell lines (LCLs) }\end{array}$ & $\begin{array}{l}\text { Sex (male) and } \\
\text { age-matched }\end{array}$ & $\begin{array}{l}87 \text { ASD and } \\
29 \text { controls }\end{array}$ & 116 & 14,834 & 6118 & $\begin{array}{l}\text { Hu WW et al. } \\
{[15]}\end{array}$ \\
\hline GSE18123 & $\begin{array}{l}\text { Blood gene expression } \\
\text { signatures distinguish } \\
\text { autism spectrum disorders } \\
\text { from controls }\end{array}$ & Whole blood & $\begin{array}{l}\text { Sex (male) and } \\
\text { age-matched }\end{array}$ & $\begin{array}{l}170 \text { ASD and } \\
115 \text { controls }\end{array}$ & 285 & 42,150 & 8575 & $\begin{array}{l}\text { Kong SW } \\
\text { et al. [32] }\end{array}$ \\
\hline GSE25507 & $\begin{array}{l}\text { Autism and increased paternal } \\
\text { age-related changes in global } \\
\text { levels of gene expression } \\
\text { regulation }\end{array}$ & $\begin{array}{l}\text { Peripheral blood } \\
\text { lymphocytes }\end{array}$ & $\begin{array}{l}\text { Sex (male) } \\
\text { matched }\end{array}$ & $\begin{array}{l}82 \text { ASD and } \\
64 \text { controls }\end{array}$ & 146 & 43,735 & 9437 & $\begin{array}{l}\text { Alter MD } \\
\text { et al. [30] }\end{array}$ \\
\hline GSE42133 & $\begin{array}{l}\text { Disrupted functional networks } \\
\text { in autism underlie early brain } \\
\text { mal-development and provide } \\
\text { accurate classification }\end{array}$ & Whole blood & $\begin{array}{l}\text { Sex (male) } \\
\text { matched }\end{array}$ & $\begin{array}{l}91 \text { ASD and } \\
56 \text { controls }\end{array}$ & 147 & 24,933 & 7873 & $\begin{array}{l}\text { Pramparo T } \\
\text { et al. [33] }\end{array}$ \\
\hline GSE6575 & $\begin{array}{l}\text { Gene expression in blood of } \\
\text { children with autism spectrum } \\
\text { disorder }\end{array}$ & Whole blood & $\begin{array}{l}\text { Sex (male) and } \\
\text { age-matched }\end{array}$ & $\begin{array}{l}35 \text { ASD and } \\
12 \text { controls }\end{array}$ & 47 & 43,745 & 9437 & $\begin{array}{l}\text { Gregg JP } \\
\text { et al. [31] }\end{array}$ \\
\hline
\end{tabular}


peripheral blood and cell lines derived from ASD individuals, the significant gene lists from the individual studies were used to create Venn diagrams (http://bioin formatics.psb.ugent.be/webtools/Venn). The DEGs found in at least two studies were selected to identify biological functions and gene regulatory networks that were enriched by Alu elements in ASD.

Identification of biological functions, canonical pathways, and gene regulatory networks associated with Alu elements in ASD

IPA (QIAGEN Inc., https://www.qiagenbioinformatics. com/products/ingenuity-pathway-analysis/) is a powerful bioinformatics tool that is helpful for understanding complex "-omics" data, such as data from microarray experiments. In this study, IPA was used to identify the biological functions, diseases, canonical pathways, and gene regulatory networks of genes that were identified in at least two studies using Fisher's exact tests with Benjamini-Hochberg correction $(\mathrm{FDR}=0.05, P$ value $<0.05)$.

\section{Experimental models and cell culture}

LCLs derived from the peripheral lymphocytes of male individuals were obtained from the Autism Genetic Resource Exchange Repository (AGRE, Los Angeles, CA, USA). Our subjects included LCLs from 36 ASD individuals and 20 sex- and age-matched unaffected controls. These individuals were previously used in large-scale clustering analysis for identification of phenotypic subgroups within ASD based on the Autism Diagnostic InterviewRevised (ADI-R) scores, as previously described in detail [14]. As a result, a total of 1954 individual ASD probands were subdivided into four phenotypic groups based on the scores of the ADI-R questionnaire. Then, we selected representative samples from the groups after excluding ASD individuals with cognitive impairment (Raven's scores < 70), known genetic or chromosomal abnormalities (e.g., Fragile X, Rett syndrome, tuberous sclerosis, chromosome 15q11-q13 duplication), or diagnosed comorbid psychiatric disorders (e.g., bipolar disorder, obsessive compulsive disorder, severe anxiety). Impairment in spoken language was also confirmed based on low standard scores $(<80)$ on the Peabody Picture Vocabulary Test. Individuals born prematurely (<35 weeks gestation) were also excluded from this study. These exclusion criteria are expected to reduce the heterogeneity of subjects to study idiopathic autism. Our LCLs represented individuals from three phenotypic groups: severe language impairment (subgroup L), milder symptoms (subgroup M), and savant skills (subgroup S). The demographic information of the LCLs used in this study is shown in Additional file 1. The LCLs were cultured according to the protocol of the Rutgers University Cell and DNA Repository, which maintains the AGRE collection of biological materials from autistic individuals and their relatives. Briefly, cells were cultured in RPMI 1640 medium supplemented with $15 \%$ fetal bovine serum and $1 \%$ penicillin/streptomycin. The cultures were split 1 : 2 every 3-4 days and harvested for DNA and RNA isolation 3 days after splitting, when the cultures were in the logarithmic growth phase.

\section{Quantitative reverse transcription-PCR analysis}

Total RNA was isolated from LCLs of ASD individuals and sex- and age-matched unaffected controls using the GENEzol Reagent (Geneaid, Taiwan) according to the manufacturer's recommended protocol. The RNA concentration was determined using a NanoDrop 1000 spectrophotometer (Thermo Scientific, USA). Quantitative reverse-transcription-PCR (RT-PCR) analysis was used to determine AluS subfamily expression in the LCLs of ASD individuals and controls. First, $5 \mu \mathrm{g}$ of extracted RNA was treated with DNase enzyme in a $10-\mu \mathrm{l}$ reaction (RQ1 RNase-Free DNase, Promega), and then, $2 \mu \mathrm{l}$ of the DNase-treated RNA was reverse-transcribed to complementary DNA (cDNA) using AccuPower ${ }^{\circledR}$ RT PreMix (Bioneer, Korea) and oligo $\mathrm{dT}_{18}$ primer in a volume of $20 \mu \mathrm{l}$, according to the manufacturer's instructions. The quantitative PCR assay was performed in triplicate using $1 \mu \mathrm{l}$ of the cDNA in master mix reactions according to the manufacturer's instructions (AccuPower ${ }^{\bullet}$ 2X GreenStar ${ }^{\mathrm{Tm}}$ qPCR MasterMix, Bioneer, Korea). The amplification cycles consisted of an initial denaturing cycle at $95{ }^{\circ} \mathrm{C}$ for $15 \mathrm{~min}$ followed by $40 \mathrm{cy}$ cles of $45 \mathrm{~s}$ at $95{ }^{\circ} \mathrm{C}$ for denaturing and $45 \mathrm{~s}$ at $60{ }^{\circ} \mathrm{C}$ for annealing/extension. Product formation was confirmed by melting curve analysis $\left(55\right.$ to $94{ }^{\circ} \mathrm{C}$ ). The AluS transcript-specific primers were as follows: forward $5^{\prime}$ GTGGCTCACGCCTGTAATC-3' and reverse 5'-GTAGAGACGGGGTTTCACCA-3'. The number of AluS transcripts was normalized to the housekeeping gene $G A P D H$ whose expression was measured using the following primer sequences (forward 5'-ATGTTCGTCATGGGTGTGAA-3' and reverse 5'-ACAGTCTTCT GGGTGGCAGT-3'), and the AluS expression level was calculated using the $2^{-\Delta \Delta C t}$ method.

\section{Determination of the Alu methylation levels and patterns} in LCLs

Genomic DNA was isolated from LCLs of ASD individuals and sex-/age-matched unaffected controls using the GENEzol Reagent (Geneaid, Taiwan) according to the manufacturer's recommended protocol. The DNA concentration was determined using a NanoDrop 1000 spectrophotometer (Thermo Scientific, USA). COBRA is designed to determine methylation levels and patterns of two CpG loci within AluS subfamilies with the highest number of copies and CpG loci in the human genome (Fig. 2a). Briefly, $1 \mu \mathrm{g}$ of genomic DNA from each 


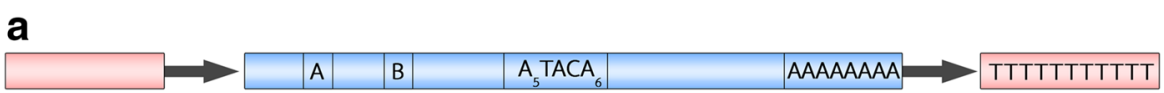

b

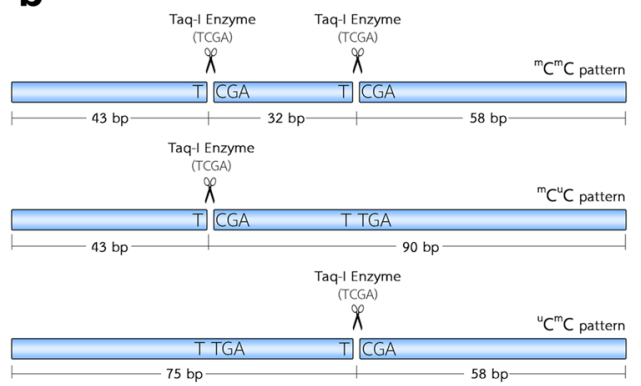

${ }^{u} \mathrm{C}^{\mathrm{C}} \mathrm{C}$ pattern
C

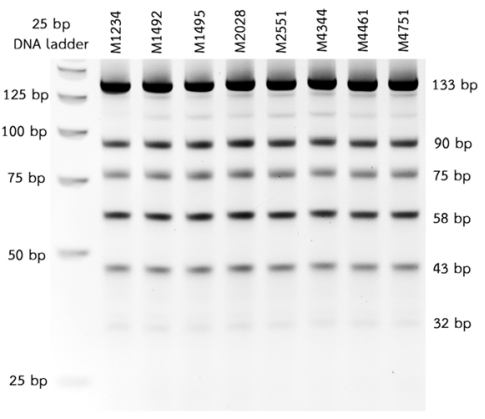

Fig. 2 Alu element structure and illustration of COBRA for determining AluS methylation levels and patterns. a Alu elements are approximately 300 bp in length and have a dimeric structure that is separated by an A-rich region $\left(A_{5} T A C A_{6}\right)$ and ends with a poly-A tail. The left half of the Alu contains the A and B boxes, which are internal promoters for RNA polymerase III. $\mathbf{b}$ Illustration of the COBRA method designed to assess methylation of two CpGs at the internal promoter of AluS subfamilies. The four different methylation patterns of AluS were calculated from the percentages of differently digested products of 133, 75, 58, 43, and 32 bp. c Representative gel image from the COBRA for AluS subfamilies

sample was treated with sodium bisulfite using EZ DNA Methylation-Gold $^{\text {ma }}$ Kit (Zymo, Irving, CA, USA). The bisulfite-treated DNA was subjected to 45 cycles of PCR (Hot Start Taq DNA polymerase, QIAGEN, USA) with two specific primers for AluS subfamilies, AluS-F (5'GGRGRGGTGGTTTARGTTTGTAA-3') and AluS-R (5' -CTAACTTTTTATATTTTTAATAAAAA-

CRAAATTTCACCA-3'), at $53{ }^{\circ} \mathrm{C}$ for annealing. Then, the AluS amplicons were digested with TaqI restriction enzyme (Thermo Scientific, USA) in TaqI buffer and incubated at $65{ }^{\circ} \mathrm{C}$ overnight. Finally, the digested products were electrophoresed on an $8 \%$ non-denaturing polyacrylamide gel, and band intensities were determined for assessment of the AluS methylation levels and patterns as described previously [26].

Upon gel electrophoresis, the digested Alu-amplicons were resolved into six fragments of $133,90,75,58,43$, and $32 \mathrm{bp}$, which represented different methylation states (Fig. 2b, c), including the ${ }^{\mathrm{u}} \mathrm{C}^{\mathrm{u}} \mathrm{C}$ methylation state (represented by the 133-bp fragment). The ${ }^{\mathrm{m}} \mathrm{C}^{\mathrm{u}} \mathrm{C}$ methylation state was represented by the 90-bp fragment. The ${ }^{\mathrm{u}} \mathrm{C}^{\mathrm{m}} \mathrm{C}$ methylation state was represented by the 75- and 58-bp fragments. The ${ }^{\mathrm{m}} \mathrm{C}^{\mathrm{m}} \mathrm{C}$ methylation state was represented by the 43- and 32-bp fragments. The calculation for percent AluS methylation was performed as follows. First, the percentage of band intensity was divided by the length (bp) of each DNA fragment: $\% 133 / 133=\mathrm{A}, \quad \% 58 / 58=\mathrm{B}, \quad \% 75 / 75=\mathrm{C}, \quad \% 90 / 90=\mathrm{D}$, $\% 43 / 43=\mathrm{E}$, and $\% 32 / 32=\mathrm{F}$. The percentages of Alu methylation levels and patterns were then calculated using the following formulas: percentage methylated loci $\left(\%{ }^{m} \mathrm{C}\right)=100 \times(\mathrm{E}+\mathrm{B}) /(2 \mathrm{~A}+\mathrm{E}+\mathrm{B}+\mathrm{C}+\mathrm{D})$, percentage of hypermethylated pattern $\left(\%{ }^{\mathrm{m}} \mathrm{C}^{\mathrm{m}} \mathrm{C}\right)=100 \times \mathrm{F} /(\mathrm{A}+\mathrm{C}+\mathrm{D}+$ F), percentage of partially methylated pattern $\left(\%{ }^{\mathrm{u}} \mathrm{C}^{\mathrm{m}} \mathrm{C}\right)=$ $100 \times C /(A+C+D+F)$, percentage of partially methylated pattern $\left(\%{ }^{\mathrm{m}} \mathrm{C}^{\mathrm{u}} \mathrm{C}\right)=100 \times \mathrm{D} /(\mathrm{A}+\mathrm{C}+\mathrm{D}+\mathrm{F})$, and percentage of partially hypomethylated pattern $\left(\%{ }^{\mathrm{u}} \mathrm{C}^{\mathrm{u}} \mathrm{C}\right)=100 \times \mathrm{A} /(\mathrm{A}$ $+\mathrm{C}+\mathrm{D}+\mathrm{F})$.

\section{Statistical analyses}

DEGs were determined using two-tailed $t$ tests with adjusted Bonferroni correction, and adjusted $P$ values less than 0.05 were considered significant. Fisher's exact test with Benjamini-Hochberg ( $F D R=0.05)$ correction was used to investigate the association between the DEG lists and the human Alu-inserted gene lists. $P$ values less than 0.05 were considered significant. Pathway and function analyses were performed with IPA using Fisher's exact test with Benjamini-Hochberg correction for multiple testing (FDR $=0.05)$; $P$ values less than 0.05 were considered significant. Two-tailed $t$ tests with BenjaminiHochberg correction (FDR $=0.05$ ) were used to analyze the differences in AluS methylation and expression level; the adjusted $P$ value threshold was 0.05 .

\section{Results}

Genes containing Alu elements are differentially expressed in ASD blood based on the integration of data from multiple studies

We hypothesized that Alu elements are associated with altered gene expression in the peripheral blood and blood-derived cell lines of ASD individuals and provided CpG sites for DNA methylation within Alu-inserted genes. To test this hypothesis, we obtained five 
transcriptome profiles from ASD studies available in GEO DataSets and identified a list of DEGs from each study. We then overlapped these DEG lists with the human Alu-inserted genes using Fisher's exact test; the results are shown in Table 3. These results showed that the DEGs in the peripheral blood of ASD individuals were significantly associated with the Alu-inserted gene lists. For the group of all Alu insertion types, the lists of DEGs (up- and downregulated genes) were significantly associated with Alu elements. These lists consist of 388, 869, 1001, and 1492 DEGs from the GSE6575, GSE25507, GSE42133, and GSE18123 studies, respectively. We subsequently identified the up- and downregulated DEGs and assessed their overlap with the "all Alu insertion" gene list type; the results showed a strong association for downregulated genes (adjusted $P$ value $<0$. 0005). However, the "all Alu insertion" type was only weakly associated with upregulated genes (adjusted $P$ value $=0.015)$ in the GSE42133 study and showed a weaker association in the other studies. DEGs were also compared with the other types of Alu insertion gene lists, including the exonic, exonized, intronic, and promoter types. The results are shown in Table 3. These results showed that the DEGs were more strongly associated with the Alu intronic lists than with the other types of Alu insertions. Intronic Alu elements were also strongly associated with the downregulated gene lists. Moreover, because the GSE15402 study has also reduced the heterogeneity of ASD by subgrouping ASD individuals based on their clinical phenotypes using supervised and unsupervised clustering analyses of ADI-R scores, we further investigated whether Alu insertions were associated with DEGs in each ASD subgroup. Interestingly, we found that genes with Alu insertion were significantly

Table 3 Association analyses between the differentially expressed genes (DEGs) in ASD and the human Alu-inserted gene lists

\begin{tabular}{|c|c|c|c|c|c|c|c|c|}
\hline \multirow{2}{*}{$\begin{array}{l}\text { Insertion } \\
\text { type }\end{array}$} & \multirow[t]{2}{*}{ Comparison } & \multirow{2}{*}{$\begin{array}{l}\text { GEO } \\
\text { datasets }\end{array}$} & \multicolumn{2}{|c|}{ All differentially expressed genes } & \multicolumn{2}{|c|}{ Upregulated genes } & \multicolumn{2}{|c|}{ Downregulated genes } \\
\hline & & & $P$ value & Genes $(n)$ & $P$ value & Genes $(n)$ & $P$ value & Genes $(n)$ \\
\hline \multirow[t]{5}{*}{ All insertion } & \multirow[t]{5}{*}{ ASD vs. control } & GSE15402 & 0.799 & 215 & 0.926 & 100 & 0.799 & 116 \\
\hline & & GSE18123 & $<0.00005$ & 1492 & 1.000 & 255 & $<0.00005$ & 1245 \\
\hline & & GSE25507 & 0.012 & 869 & 0.256 & 522 & $<0.00005$ & 355 \\
\hline & & GSE42133 & $<0.00005$ & 1001 & 0.015 & 387 & $<0.00005$ & 624 \\
\hline & & GSE6575 & $<0.00005$ & 388 & 0.955 & 123 & $<0.00005$ & 266 \\
\hline \multirow[t]{5}{*}{ Intronic } & \multirow[t]{5}{*}{ ASD vs. control } & GSE15402 & 0.784 & 212 & 0.926 & 99 & 0.784 & 114 \\
\hline & & GSE18123 & $<0.00005$ & 1476 & 0.970 & 252 & $<0.00005$ & 1231 \\
\hline & & GSE25507 & 0.007 & 860 & 0.322 & 516 & $<0.00005$ & 352 \\
\hline & & GSE42133 & $<0.00005$ & 985 & 0.012 & 382 & $<0.00005$ & 613 \\
\hline & & GSE6575 & $<0.00005$ & 382 & 0.882 & 119 & $<0.00005$ & 264 \\
\hline \multirow[t]{5}{*}{ Exonized } & \multirow[t]{5}{*}{ ASD vs. control } & GSE15402 & 1.000 & 15 & 0.933 & 6 & 0.933 & 9 \\
\hline & & GSE18123 & 0.009 & 102 & 0.926 & 14 & 0.003 & 88 \\
\hline & & GSE25507 & 0.825 & 45 & 0.008 & 17 & 0.012 & 28 \\
\hline & & GSE42133 & 0.008 & 75 & 0.306 & 27 & 0.015 & 49 \\
\hline & & GSE6575 & 0.006 & 33 & 1.000 & 7 & $<0.00005$ & 26 \\
\hline \multirow[t]{5}{*}{ Exonic } & \multirow[t]{5}{*}{ ASD vs. control } & GSE15402 & 0.450 & 19 & 0.904 & 10 & 0.426 & 9 \\
\hline & & GSE18123 & 0.001 & 177 & 0.306 & 21 & $<0.00005$ & 158 \\
\hline & & GSE25507 & 0.426 & 78 & 0.136 & 46 & 0.662 & 33 \\
\hline & & GSE42133 & $<0.00005$ & 148 & 0.799 & 43 & $<0.00005$ & 106 \\
\hline & & GSE6575 & 0.034 & 48 & 0.715 & 16 & 0.013 & 33 \\
\hline \multirow[t]{5}{*}{ Promoter } & \multirow[t]{5}{*}{ ASD vs. control } & GSE15402 & 0.933 & 6 & 0.436 & 1 & 0.799 & 5 \\
\hline & & GSE18123 & 0.240 & 37 & 0.898 & 8 & 0.268 & 29 \\
\hline & & GSE25507 & 0.135 & 22 & 0.033 & 11 & 0.937 & 11 \\
\hline & & GSE42133 & 0.831 & 35 & 0.447 & 19 & 0.255 & 16 \\
\hline & & GSE6575 & 0.466 & 16 & 0.716 & 3 & 0.123 & 13 \\
\hline
\end{tabular}

The list of DEGs from each gene expression profiling study was overlapped with the lists of Alu-inserted genes. Alu-inserted genes were categorized into five types of Alu insertions which included exonized, exonic, intronic, promoter, and combined insertion types. Fisher's exact test with Benjamini-Hochberg correction (FDR $=0.05$ ) was used to determine the association the DEGs and Alu-inserted genes, and $P$ values of less than 0.05 were considered significant. The number of DEGs and adjusted $P$ values are shown 
associated with DEGs in ASD subgroups but not when all ASD cases were combined (Additional file 2).

We subsequently selected the lists of downregulated genes that were significantly associated with all Alu insertion lists from each study. These lists were used to identify overlapping genes among the selected studies using Venn diagram analysis (Fig. 3). Interestingly, the diagram revealed the reproducibility of Alu-inserted genes that were differentially expressed in ASD whole blood/blood cells. Significant genes that were identified in at least two studies (320 overlapping genes; see Additional file 3) were selected to identify gene regulatory networks, diseases, and biological functions that were associated with Alu elements in ASD.

\section{Biological functions, canonical pathways, and gene regulatory networks of dysregulated genes containing Alu elements are associated with neurological functions and neurodevelopmental disorders}

IPA was used to predict the diseases, biological functions, canonical pathways, and gene regulatory networks that were associated with Alu elements in ASD. The results showed that the overlapping genes (320 genes) were significantly associated with neurological diseases and nervous system development and function (adjusted Fisher's exact test, $P$ value $<0.05$ ) (Table 4 ). Interestingly, 21 overlapping genes were associated with autism or intellectual disability. Eighteen and 20 of the overlapping genes were also associated with mental retardation and cognitive impairment, respectively, which were classified as neurodevelopmental disorders comorbid with ASD. The IPA results also revealed significant canonical

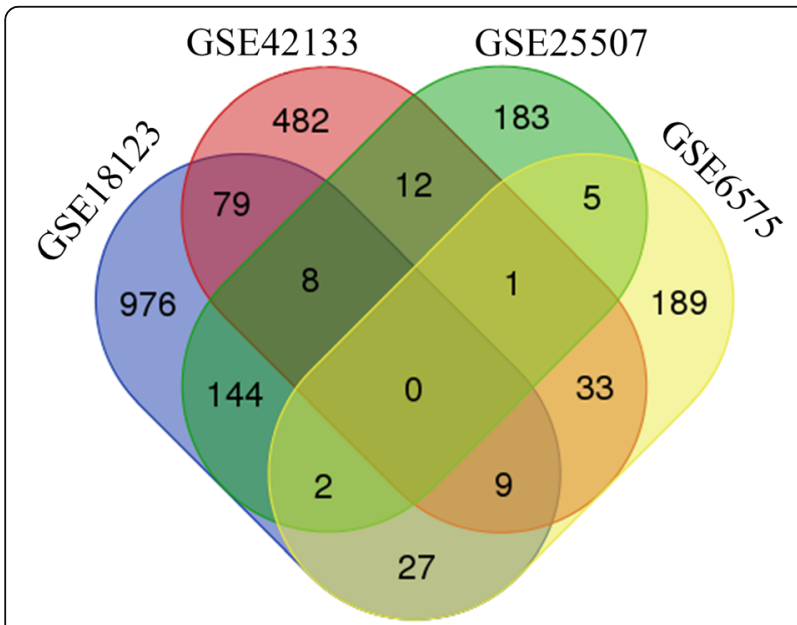

Fig. 3 Venn diagram of genes containing Alu that are differentially expressed in ASD. The significant DEGs with Alu insertions from each study based on Fisher's exact test overlapped. The diagram shows the reproducibility of Alu-inserted genes that were differentially expressed in peripheral blood and blood-derived cell lines from ASD individuals. A total of 320 genes were selected to identify biological functions and gene regulatory networks through an Ingenuity Pathway Analysis (IPA) pathways associated with the overlapping genes (Table 5) , including neurotrophin/TRK signaling, ERK/MAPK signaling, axonal guidance signaling, CREB signaling in neurons, estrogen receptor signaling, androgen signaling, IL-6 signaling, and neuroinflammation signaling, all of which have been associated with ASD.

Gene regulatory networks are sets of genes that interact to control a specific cell function, including cell differentiation, metabolism, cell cycle, and response to environmental cues. A representative gene network associated with neurological disease (Fig. 4) revealed the interaction of overlapping genes with additional molecules from the IPA database involved in estrogen receptor and androgen signaling, axonal guidance signaling, CREB signaling in neurons, and neurotrophin/ TRK signaling. This network suggested that some ASDrelated biological pathways are associated with Alu-inserted DEGs in the blood of ASD individuals.

\section{AluS methylation levels and patterns in LCLs}

To determine the levels of DNA methylation within Alu elements, which contributes to a large proportion of the CpG sites in the human genome, we used LCLs as a model and conducted a COBRA. Specifically, a COBRA of AluS subfamilies was performed to determine the percentages of AluS methylation levels $\left({ }^{\mathrm{m}} \mathrm{C}\right)$ and patterns $\left({ }^{\mathrm{m}} \mathrm{C}^{\mathrm{m}} \mathrm{C},{ }^{\mathrm{m}} \mathrm{C}^{\mathrm{u}} \mathrm{C},{ }^{\mathrm{u}} \mathrm{C}^{\mathrm{m}} \mathrm{C},{ }^{\mathrm{u}} \mathrm{C}^{\mathrm{u}} \mathrm{C}\right)$ in LCLs, and the results showed that comparisons of the AluS methylation levels and patterns between the ASD $(n=36)$ and sex- and age-matched unaffected control $(n=20)$ groups were not significantly different (Table 6). The levels and patterns of Alu methylation in individual LCLs are shown in Additional file 4. Due to heterogeneity within ASD individuals, our LCLs were categorized into three subgroups, namely, savant $(\mathrm{S})$, mild $(\mathrm{M})$, and language-impaired (L), based on the ADI-R interview scores according to $\mathrm{Hu}$ and Steinberg [14]. In addition, $\mathrm{Hu}$ and colleagues reported that the gene expression profiles of LCLs were significantly different among these ASD subgroups [15].

We then compared the AluS methylation levels and patterns between each ASD subgroup and the sex- and age-matched groups. Interestingly, the results showed significant AluS methylation patterns associated with specific ASD subgroups. The percentage of the partially methylated pattern ${ }^{\mathrm{u}} \mathrm{C}^{\mathrm{m}} \mathrm{C}(20.06 \% \pm 0.92 \%$, adjusted $P$ value $=0.043)$ was significantly increased in ASD subgroup $M$ (Table 6, Fig. 5). In addition, the percentage of the partially methylated pattern ${ }^{\mathrm{m}} \mathrm{C}^{\mathrm{u}} \mathrm{C}(20.43 \% \pm 1$. $17 \%$, adjusted $P$ value $=0.010$ ) was significantly decreased in ASD subgroup S compared with sex- and age-matched controls. There were no significant patterns of AluS methylation in ASD subgroup L. These findings suggested that methylation of Alu elements might play a role in AluS expression and/or transcriptional profile of some ASD subgroups but not all ASD individuals. 
Table 4 Diseases and biological functions associated with reproducible DEGs with Alu insertion predicted by the Ingenuity Pathway Analysis (IPA)

\begin{tabular}{|c|c|c|c|}
\hline $\begin{array}{l}\text { Disease or function } \\
\text { annotation }\end{array}$ & $\begin{array}{l}\text { Benjamini-Hochberg } \\
P \text { value }\end{array}$ & $\begin{array}{l}\text { No. of } \\
\text { genes }\end{array}$ & Gene symbol \\
\hline $\begin{array}{l}\text { Autism or intellectual } \\
\text { disability }\end{array}$ & $2.19 \mathrm{E}-04$ & 21 & $\begin{array}{l}\text { ABCB1, ADNP, ANKRD11, ARID1A, ATP6V1A, CAMTA1, CASP2, CDC42, CHD4, COL4A3BP, } \\
\text { CREBBP, GNB1, OPA1, PTEN, SLC35A3, SMARCA2, SON, TRIO, UBE3A, YY1, ZMYND11 }\end{array}$ \\
\hline $\begin{array}{l}\text { Neuromuscular } \\
\text { disease }\end{array}$ & $5.70 \mathrm{E}-04$ & 34 & $\begin{array}{l}\text { ABCB1, ADAM10, ALCAM, ANKRD11, ATP2A2, ATP6V1A, ATXN1, CANX, CASP2, CFLAR, GSK3B, } \\
\text { HBP1, HMGCR, HSPA5, IFNAR2, IL7R, KIF1B, LDLR, MAP2K4, MBP, MBTPS1, NOTCH2, OSBPL8, } \\
\text { PPP3CB, PTPRC, PTPRE, RUNX3, SSX2IP, TLR2, TOMM20, TRIO, USP13, WNK1, XRCC6 }\end{array}$ \\
\hline $\begin{array}{l}\text { Synthesis of reactive } \\
\text { oxygen species }\end{array}$ & $7.52 \mathrm{E}-04$ & 14 & $\begin{array}{l}\text { CANX, CDC42, CYBB, ETS1, FCER1A, HGF, ITGB1, MAP2K4, MAPK1, PIK3CG, PTEN, SHC1, TLR2, } \\
\text { TXNRD1 }\end{array}$ \\
\hline $\begin{array}{l}\text { Disorder of basal } \\
\text { ganglia }\end{array}$ & $9.21 \mathrm{E}-04$ & 29 & $\begin{array}{l}\text { ABCB1, ANKRD11, ATP2A2, ATP6V1A, ATXN1, CA2, CASP2, CFLAR, GSK3B, HBP1, HMGCR, } \\
\text { HSPA5, KIF1B, LDLR, MAP2K4, MBP, MBTPS1, NOTCH2, OSBPL8, PTPRE, RUNX3, SAMHD1, } \\
\text { SSX2IP, TOMM20, TRIO, USP13, WNK1, XPR1, XRCC6 }\end{array}$ \\
\hline Dyskinesia & $9.44 \mathrm{E}-04$ & 23 & $\begin{array}{l}\text { ABCB1, ANKRD11, ATP2A2, ATP6V1A, ATXN1, CASP2, CFLAR, HBP1, HMGCR, HSPA5, LDLR, } \\
\text { MAP2K4, MBTPS1, NOTCH2, OSBPL8, PTPRE, RUNX3, SSX2IP, TOMM20, TRIO, USP13, WNK1, } \\
\text { XRCC6 }\end{array}$ \\
\hline Mental retardation & $1.13 \mathrm{E}-03$ & 18 & $\begin{array}{l}\text { ADNP, ANKRD11, ARID1A, ATP6V1A, CAMTA1, CASP2, CDC42, CHD4, COL4A3BP, CREBBP, } \\
\text { GNB1, OPA1, SLC35A3, SMARCA2, SON, TRIO, YY1, ZMYND11 }\end{array}$ \\
\hline Brain lesion & $1.36 \mathrm{E}-03$ & 33 & $\begin{array}{l}\text { ANKRD11, ANXA7, APC, ARCN1, ARID1A, ATP6V1A, CA2, CBL, CREBBP, CTBP2, DICER1, DOCK5, } \\
\text { EHD4, HGF, HMGCR, IRS2, LDLR, LYST, NCOA1, NF1, PABPC1, PIK3R1, PRKCSH, PTEN, PTPN11, } \\
\text { SAP130, SON, TBK1, TOP1, TRIM33, TRIP11, TRRAP, ZCCHC6 }\end{array}$ \\
\hline $\begin{array}{l}\text { Cognitive } \\
\text { impairment }\end{array}$ & $1.44 \mathrm{E}-03$ & 20 & $\begin{array}{l}\text { ADNP, ANKRD11, ARID1A, ATP6V1A, CA2, CAMTA1, CASP2, CDC42, CHD4, COL4A3BP, CREBBP } \\
\text { GNB1, HMGCR, OPA1, SLC35A3, SMARCA2, SON, TRIO, YY1, ZMYND11 }\end{array}$ \\
\hline Dementia & $1.62 \mathrm{E}-03$ & 27 & $\begin{array}{l}\text { ADAM10, APLP2, ATXN1, CA2, CANX, CASP2, DICER1, GSK3B, HMGCR, HSPA5, LDLR, LIMS1, } \\
\text { NFE2L2, OPA1, PIK3R1, PTEN, PTPRE, RUNX3, SLC6A6, SMPD1, SPG21, SRPK2, TBK1, TFCP2, } \\
\text { TRIO, UBQLN1, WDR7 }\end{array}$ \\
\hline
\end{tabular}

Neurological diseases and functions are significantly associated with 320 overlapping genes that were identified in multiple studies. $P$ values calculated by Fisher's exact test with Benjamini-Hochberg correction $(F D R=0.05)$ and the number of genes for each function are shown

\section{Quantitative reverse transcription-PCR analysis of the AluS expression levels in 56 LCLs}

To understand the influence of DNA methylation within AluS elements on AluS expression levels, a quantitative RT-PCR analysis was performed using the LCLs of ASD and sex- and age-matched unaffected control groups. The results showed no significant differences in AluS expression between the ASD and the matched control groups (fold change $(\mathrm{FC})=1.75$, adjusted $P$ value 0.316 , Table 7), which was similar to the results obtained from the AluS methylation level and pattern analyses. However, comparisons of the AluS expression levels between the ASD phenotypic subgroups and sex- and agematched control groups revealed that these were significantly different. Specifically, the AluS expression levels were significantly decreased in ASD subgroup $\mathrm{L}(\mathrm{FC}=0$. 29 , adjusted $P$ value $=0.032$ ) and significantly increased in ASD subgroup $\mathrm{S}(\mathrm{FC}=3.68$, adjusted $P$ value $=0.038)$. However, in ASD subgroup $M$, the AluS expression level was not significantly different.

\section{Correlation analysis between AluS methylation levels and AluS expression levels}

To demonstrate that AluS methylation regulates the expression of AluS elements, we correlated the DNA methylation and expression levels of AluS subfamilies in the LCLs from ASD individuals and sex- and agematched controls. The correlation analyses revealed non-linear relationships between DNA methylation and the expression of AluS subfamilies in all groups (ASD + control, Fig. 6). However, when analyzed within the ASD subgroups, we found that the partially methylated pattern ${ }^{\mathrm{u}} \mathrm{C}^{\mathrm{m}} \mathrm{C}$ showed a moderate positive relationship with AluS expression in ASD subgroup M (coefficient $r=0$. 5149, Fig. 7), whereas other AluS methylation patterns did not correlate with ASD subgroup M. Similarly, DNA methylation and expression of AluS subfamilies were not correlated in ASD subgroups L and S (Additional files 5 and 6). These findings suggested that the partially methylated pattern ${ }^{\mathrm{u}} \mathrm{C}^{\mathrm{m}} \mathrm{C}$ might regulate the expression of AluS elements in ASD subgroup $M$.

\section{Discussion}

The mechanisms through which human Alu elements are involved in ASD are unclear. In a previous study, Mbarek et al. found a polymorphism of an Alu element in the blood of ASD individuals with more severe clinical symptoms [27]. This allele is located in intron 27b of the neurofibromatosis type 1 (NF1) gene, which is reported to be an ASD risk gene. However, substantially more information was needed to conclude that Alu elements play important roles in ASD. Our findings provide 
Table 5 Canonical pathways associated with reproducible DEGs with Alu insertion predicted by the Ingenuity Pathway Analysis (IPA)

\begin{tabular}{|c|c|c|}
\hline Ingenuity canonical pathways & $\begin{array}{l}\text { Benjamini-Hochberg } \\
P \text { value }\end{array}$ & Gene symbol \\
\hline ILK signaling & $6.39 \mathrm{E}-08$ & $\begin{array}{l}\text { PPP2R5E, GSK3B, CDC42, PTEN, IRS2, CREB1, PIK3R4, RHOQ, PIK3R1, MYH9, PIK3CG, } \\
\text { PTPN11, MAP2K4, ITGB1, MAPK1, CREBBP, LIMS1, FNBP1, NACA }\end{array}$ \\
\hline Neurotrophin/TRK signaling & $3.20 \mathrm{E}-07$ & $\begin{array}{l}\text { CDC42, MAP3K5, IRS2, CREB1, PTPN11, MAP2K4, PIK3R4, MAPK1, CREBBP, PIK3R1, } \\
\text { SHC1, PIK3CG }\end{array}$ \\
\hline NGF signaling & $5.11 \mathrm{E}-07$ & $\begin{array}{l}\text { CDC42, MAP3K5, IRS2, CREB1, PIK3R4, SMPD1, PIK3R1, PIK3CG, PTPN11, MAP2K4, } \\
\text { TRIO, MAPK1, CREBBP, SHC1 }\end{array}$ \\
\hline Reelin signaling in neurons & $1.02 \mathrm{E}-06$ & GSK3B, ITGAL, IRS2, FYN, PTPN11, MAP2K4, ITGB1, PIK3R4, PIK3R1, YES1, LYN, PIK3CG \\
\hline HGF signaling & 1.24E-06 & $\begin{array}{l}\text { CDC42, MAP3K5, IRS2, PIK3R4, ELF2, PIK3R1, PIK3CG, PTPN11, MAP2K4, ITGB1, MAPK1, } \\
\text { ETS1, HGF }\end{array}$ \\
\hline ERK/MAPK signaling & $2.73 \mathrm{E}-06$ & $\begin{array}{l}\text { PPP2R5E, PAK2, IRS2, CREB1, PIK3R4, ELF2, PRKAG2, PIK3R1, PIK3CG, FYN, PTPN11, } \\
\text { ITGB1, MAPK1, CREBBP, ETS1, SHC1 }\end{array}$ \\
\hline Insulin receptor signaling & 5.09E-06 & $\begin{array}{l}\text { GSK3B, PTEN, IRS2, PIK3R4, PRKAG2, RHOQ, PIK3R1, CBL, PIK3CG, FYN, PTPN11, MAPK1, } \\
\text { SHC1 }\end{array}$ \\
\hline Axonal guidance signaling & 2.47E-05 & $\begin{array}{l}\text { SEMA4D, GSK3B, CDC42, PAK2, IRS2, PIK3R4, PLXNC1, GNB1, PPP3CB, PRKAG2, ADAM10, } \\
\text { PIK3R1, RASSF5, PIK3CG, GNAI2, FYN, PPP3R1, PTPN11, ITGB1, MAPK1, PLCL2, SHC1 }\end{array}$ \\
\hline IL-6 signaling & 4.05E-05 & ABCB1, MAP4K4, IRS2, PTPN11, MAP2K4, PIK3R4, MAPK1, PIK3R1, SHC1, IL6ST, PIK3CG \\
\hline $\begin{array}{l}\text { Neuroinflammation } \\
\text { signaling pathway }\end{array}$ & $4.51 \mathrm{E}-05$ & $\begin{array}{l}\text { GSK3B, IRS2, CREB1, PIK3R4, PPP3CB, PIK3R1, TBK1, PIK3CG, CFLAR, PPP3R1, PTPN11, } \\
\text { MAP2K4, MAPK1, CREBBP, CYBB, TLR2, NFE2L2 }\end{array}$ \\
\hline $\begin{array}{l}\text { Glucocorticoid receptor } \\
\text { signaling }\end{array}$ & 4.78E-05 & $\begin{array}{l}\text { IRS2, CREB1, NCOA1, PIK3R4, SMARCA2, PPP3CB, PRKAG2, PIK3R1, PIK3CG, TAF4, PPP3R1, } \\
\text { PTPN11, MAP2K4, HSPA5, MAPK1, CREBBP, ARID1A, SHC1 }\end{array}$ \\
\hline PI3K/AKT signaling & $1.22 \mathrm{E}-04$ & PPP2R5E, GSK3B, MAP3K5, PTEN, ITGB1, MAPK1, LIMS1, PIK3R1, SHC1, PIK3CG \\
\hline CREB signaling in neurons & 1.49E-04 & $\begin{array}{l}\text { IRS2, CREB1, PIK3R4, GNB1, PRKAG2, PIK3R1, PIK3CG, GNAI2, PTPN11, MAPK1, CREBBP, } \\
\text { PLCL2, SHC1 }\end{array}$ \\
\hline Synaptic long-term potentiation & $6.29 \mathrm{E}-03$ & PPP3R1, CREB1, PPP3CB, MAPK1, CREBBP, PRKAG2, PLCL2 \\
\hline Estrogen receptor signaling & $9.05 \mathrm{E}-03$ & TAF4, NCOA1, CTBP2, MAPK1, CREBBP, TRRAP, SHC1 \\
\hline Androgen signaling & 1.19E-02 & GNAI2, NCOA1, GNB1, MAPK1, CREBBP, PRKAG2, SHC1 \\
\hline
\end{tabular}

Canonical pathways are significantly associated with 320 overlapping genes that were identified in multiple studies. $P$ values calculated by Fisher's exact test with Benjamini-Hochberg correction (FDR $=0.05)$ for each function are shown

preliminary information regarding the association between DEGs and Alu elements in the peripheral blood samples of ASD individuals. It is important to note that Alu elements have the potential to influence gene expression through insertion into the gene structure and through the contribution of gene regulatory elements, such as transcription binding sites and CpG sites [17]. Moreover, Alu elements can act as enhancers, alternate promoters, transcription start sites, and inhibitors of transcription via heterochromatin formation $[28,29]$.

Several studies have reported altered gene expression profiles in the peripheral blood or blood-derived cell lines of ASD individuals [15, 30-33]. However, no studies have identified an association between DEGs in ASD and Alu elements that could influence gene expression. We first performed multiple gene expression profile comparisons with human Alu-inserted genes in ASD samples using Fisher's exact test. Interestingly, we found that the Alu-inserted genes were associated with DEGs in ASD individuals in four studies (Table 3). These results indicated a strong association of Alu insertion with downregulated genes in ASD, suggesting that Alu elements could affect gene downregulation. Another interesting question is whether the specific Alu-inserted positions are associated with gene regulation. For this analysis, the Alu-inserted gene list was categorized into four types of Alu insertions: intronic, exonized, exonic, and promoter inserts. Interestingly, we found that intronic Alu insertion was significantly associated with DEGs in ASD invididuals. According to a previous study by Tsirigos et al., a genome-wide computational analysis showed that Alu elements selectively retained in the intronic region of inserted genes were associated with specific functions, including the regulation of transcription, RNA processing and splicing, and translation [34]. However, it remains unclear how intronic Alu insertions can influence the expression of genes associated with ASD-related biological functions, and this topic should be investigated further in future research.

We then explored the biological functions associated with 320 DEGs with Alu insertions that overlapped between the selected studies. These overlapping genes were significantly associated with autism or intellectual disability and ASD co-morbid disorders, including 


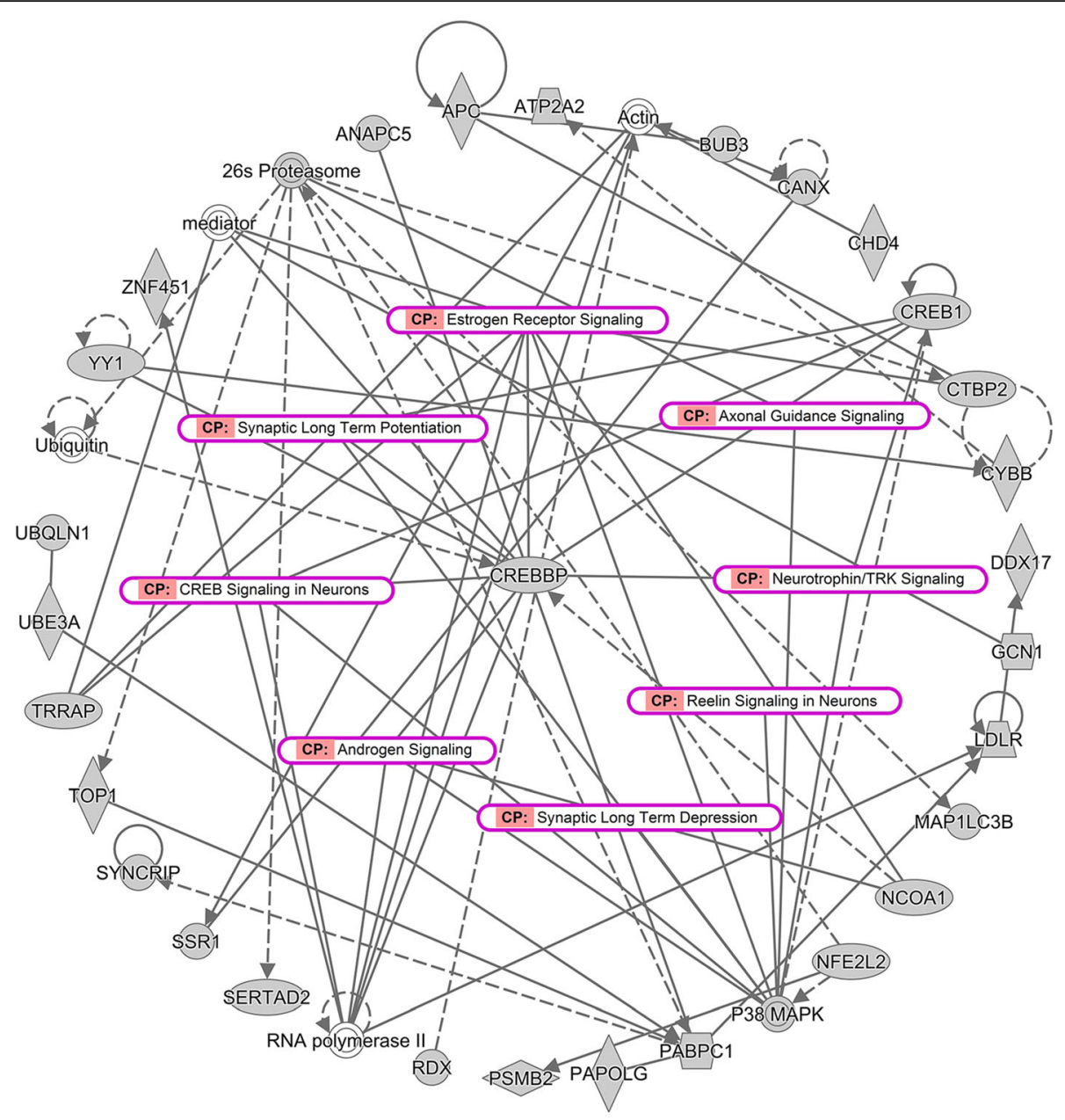

Fig. 4 Predicted gene regulatory network of the overlapping genes associated with neurological disease. This network revealed interactions or relationships among the overlapping molecules (gray background) and with other molecules from the IPA database (white background) that play a role in several mechanisms associated with neurological disease and estrogen receptor and androgen signaling, which is known to be associated with sex bias in ASD (labeled pink)

mental retardation and cognitive impairment. It is noteworthy that sex hormone signaling pathways, including estrogen receptor signaling and androgen signaling pathways, were also associated with DEGs containing Alu elements. ASD is biased towards males with a male-tofemale ratio of at least $4: 1$, and there is accumulating evidence showing that sex hormones and related pathways may play an important role in the sex bias of ASD [35-37]. Recent studies have found that high testosterone exposure during pregnancy significantly correlates with the development of ASD, social development, and language development [38-40]. Moreover, the expression levels of estrogen receptor mRNA and protein were found to be reduced in the brain tissues and serum of ASD individuals [41, 42]. Interestingly, one of the DEGs with Alu insertion related to estrogen receptor and androgen signaling is $N C O A 1$, which is a gene encoding the nuclear receptor coactivator 1 protein. This coregulatory protein has been reported to interact with estrogen receptor and androgen receptor, which oppositely regulate the transcription of the RORA gene encoding the retinoic acid-related (RAR) orphan receptor-alpha (RORA) protein [36]. RORA is a hormone-dependent transcription factor that regulates many genes, including CYP19A1 (aromatase), an enzyme that converts testosterone to estrogen [37, 43-45]. Our previous study also found that RORA binds NCOA1 and regulates the transcription of the CYP19A1 gene [36]. Thus, it is possible that Alu elements are associated with the sex bias of ASD by disrupting the androgen receptor/estrogen receptor-mediated regulation of RORA and CYP19A1. Other interesting pathways that are known to be associated with ASD include neurotrophin/TRK signaling [46], ERK/MAPK signaling [47], axonal guidance signaling [48], CREB signaling in neurons [49], IL-6 signaling [50], and neuroinflammation signaling [51]. 
Table 6 COBRA-derived percentages of AluS methylation and patterns in LCLs from ASD individuals and sex-and age-matched controls

\begin{tabular}{|c|c|c|c|c|c|c|c|}
\hline \multirow[t]{2}{*}{ Comparison } & \multirow[t]{2}{*}{ Sample groups } & \multirow[t]{2}{*}{ Age $($ mean $\pm S D)$} & \multicolumn{5}{|c|}{ Percentages of AluS methylation patterns } \\
\hline & & & $\%^{m} \mathrm{C}$ & $\%^{m} C^{m} C$ & ${ }^{\mathrm{u}} \mathrm{C}^{\mathrm{m}} \mathrm{C}$ & $\%^{\mathrm{m}} \mathrm{C}^{\mathrm{u}} \mathrm{C}$ & $\%{ }^{\mathrm{u}} \mathrm{C}^{\mathrm{u}} \mathrm{C}$ \\
\hline \multirow{3}{*}{$\begin{array}{l}\text { ASD vs. control (sex- and } \\
\text { age-matched) }\end{array}$} & Control $(n=20)$ & $15 \pm 6.97$ & $37.98 \pm 1.36$ & $25.70 \pm 2.36$ & $18.71 \pm 1.15$ & $21.76 \pm 1.03$ & $33.83 \pm 1.69$ \\
\hline & $\operatorname{ASD}(n=36)$ & $13.4 \pm 4.55$ & $37.86 \pm 2.07$ & $25.92 \pm 2.69$ & $18.72 \pm 1.66$ & $21.22 \pm 1.76$ & $34.13 \pm 3.00$ \\
\hline & $P$ value & & 0.866 & 0.866 & 0.974 & 0.315 & 0.845 \\
\hline \multirow{3}{*}{$\begin{array}{l}\text { Subgroup M vs. control } \\
\text { (sex- and age-matched) }\end{array}$} & Control $(n=10)$ & $12.1 \pm 3.81$ & $38.07 \pm 1.52$ & $25.57 \pm 2.31$ & $18.76 \pm 0.87$ & $22.06 \pm 0.69$ & $33.62 \pm 1.85$ \\
\hline & ASD subgroup M $(n=10)$ & $12.1 \pm 3.73$ & $39.03 \pm 1.16$ & $25.17 \pm 1.15$ & $20.06 \pm 0.92$ & $22.99 \pm 0.82$ & $31.77 \pm 1.76$ \\
\hline & $P$ value & & 0.293 & 0.845 & 0.043 & 0.089 & 0.168 \\
\hline \multirow{3}{*}{$\begin{array}{l}\text { Subgroup L vs. control } \\
\text { (sex- and age-matched) }\end{array}$} & Control $(n=6)$ & $13.7 \pm 1.64$ & $37.84 \pm 1.51$ & $24.88 \pm 2.94$ & $19.10 \pm 1.60$ & $22.25 \pm 1.03$ & $33.77 \pm 1.84$ \\
\hline & ASD subgroup $L(n=6)$ & $13.5 \pm 1.97$ & $36.024 \pm 1.43$ & $23.37 \pm 2.63$ & $19.32 \pm 1.69$ & $20.93 \pm 2.52$ & $36.38 \pm 2.29$ \\
\hline & $P$ value & & 0.168 & 0.569 & 0.866 & 0.502 & 0.168 \\
\hline \multirow{3}{*}{$\begin{array}{l}\text { Subgroup S vs. control } \\
\text { (sex- and age-matched) }\end{array}$} & Control $(n=20)$ & $15 \pm 6.97$ & $37.98 \pm 1.36$ & $25.70 \pm 2.36$ & $18.71 \pm 1.15$ & $21.76 \pm 1.03$ & $33.83 \pm 1.69$ \\
\hline & ASD subgroup $S(n=20)$ & $15 \pm 5.41$ & $37.83 \pm 2.23$ & $27.06 \pm 2.67$ & $17.88 \pm 1.44$ & $20.43 \pm 1.17$ & $34.64 \pm 3.00$ \\
\hline & $P$ value & & 0.866 & 0.242 & 0.168 & 0.010 & 0.502 \\
\hline
\end{tabular}

The percentages of AluS methylation patterns were determined based on four patterns: the hypermethylated pattern $\left({ }^{\mathrm{m}} \mathrm{C}{ }^{\mathrm{m}} \mathrm{C}\right)$, two partially methylated patterns $\left({ }^{\mathrm{m}} \mathrm{C}^{\mathrm{u}} \mathrm{C},{ }^{\mathrm{u}} \mathrm{C}^{\mathrm{m}} \mathrm{C}\right)$, and the hypomethylated pattern $\left({ }^{\mathrm{u}} \mathrm{C}{ }^{\mathrm{u}} \mathrm{C}\right)$. Comparisons of the methylation status between ASD and sex- and age-matched unaffected control groups and between ASD phenotypic subgroups and the matched unaffected controls were also performed. Statistically significant $P$ values $<0.05$ with Benjamini-Hochberg correction $(F D R=0.05)$ are shown in italics

Although these biological functions and pathways associated with DEGs in ASD with Alu element insertion have been strongly implicated in ASD, we cannot exclude the possibility that all Alu-inserted genes might be enriched for these functions or pathways, regardless of whether they exhibit differential expression in ASD. The full list of Alu-inserted genes could have been used for IPA analysis as a control to address this question. However, IPA does not allow the use of a gene list larger than 8000 genes. This issue should be investigated in future research studies using other pathway analysis programs.

To date, several DMVs at specific CpG sites or DMRs have been identified in many ASD tissue types, including LCLs [9], whole blood [10], and brain [11]. However, these studies did not cover noncoding regions, including repetitive sequences and retrotransposons. DNA methylation is the major epigenetic mechanism that represses retrotransposons in the human genome, particularly Alu elements due to their relatively high CpG density [18, 52, 53]. Kochanek and colleagues found that DNA methylation at $\mathrm{CpG}$ sites within an internal promoter (B box) of Alu elements could inhibit their transcriptional activity [54]. In this study, we also assessed the DNA methylation and expression level of AluS subfamilies that contributed the most Alu element copies and CpG sites in the human genome [18]. COBRA of AluS was designed to measure $\mathrm{CpG}$ methylation at the internal promoter, including the B box, in LCLs from ASD patients and sex- and age-matched controls. The LCLs were representative samples from three phenotypic groups based on previous multivariate cluster analyses of ADI-R scores of 1954 individuals with ASD. Our results revealed that the AluS methylation levels and patterns in the LCLs of the combined group of ASD individuals compared with sex- and age-control groups were not significantly different. However, when LCLs were divided into phenotypic subgroups, the AluS methylation patterns in two of the ASD subgroups were significantly different compared with those in the sexand age-matched controls. In the ASD subgroup with mild symptoms (M), the AluS methylation pattern ${ }^{\mathrm{u}} \mathrm{C}^{\mathrm{m}} \mathrm{C}$ was increased compared with that in the sex- and agematched controls. Furthermore, the AluS methylation pattern ${ }^{\mathrm{m}} \mathrm{C}^{\mathrm{u}} \mathrm{C}$ was reduced in the ASD subgroup with savant skill (S) compared with the sex- and age-matched controls. Although the abovementioned methylation patterns are statistically significant within a specific ASD subtype, it is also worth noting that other AluS methylation patterns were not much altered in ASD in comparison with control groups. One possible explanation is that AluS elements may be dysregulated only at certain sites in the genome, such as in exonic regions. However, the COBRA analysis used in this study does not measure methylation of AluS at specific genomic locations. Thus, it is likely that signals from significant methylation sites were dampened by noise from a large number of Alu elements located in other non-significant sites in the genome.

We then measured the expression of AluS in the LCLs from the subgroups of ASD and found that AluS was over-expressed in ASD subgroup $S$ and downregulated in the ASD subgroup with severe language impairment (L) relative to their respective sex- and age-matched controls. To investigate whether DNA methylation patterns regulated the expression of Alu elements, we 

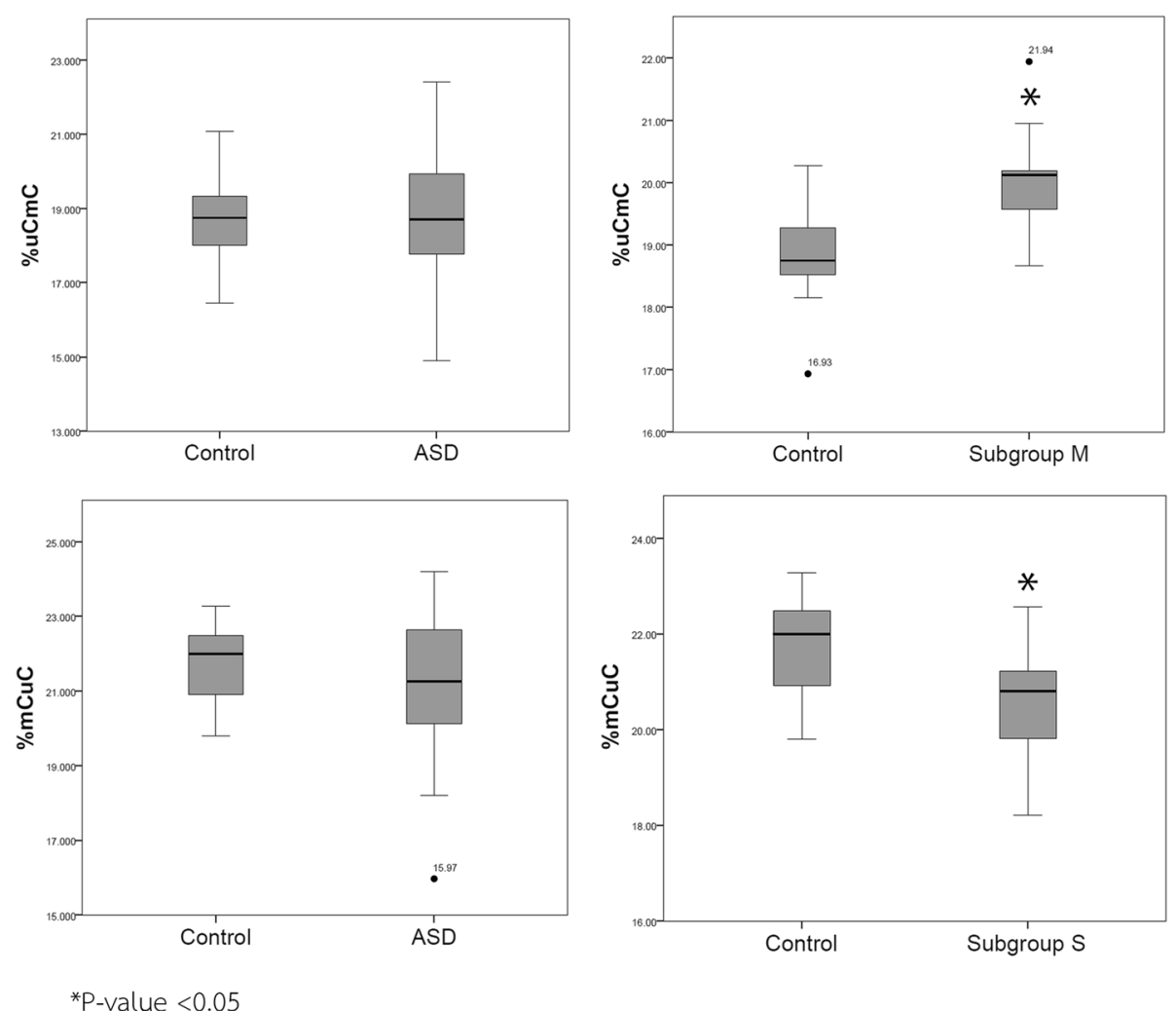

Fig. 5 Box plot of the Alu methylation patterns in the LCLs of ASD subgroup M. In ASD subgroup M, the percentage of the partially methylated pattern ${ }^{u} C{ }^{m} C$ $(20.06 \% \pm 0.92 \%)$ was significantly increased. In ASD subgroup $\mathrm{S}$, the partially methylated pattern ${ }^{\mathrm{m}} \mathrm{C}^{\mathrm{U}} \mathrm{C}$ was significantly decreased. ${ }^{*}$ adjusted $P$ value $<0.05$

analyzed the correlations between AluS methylation and expression levels. A positive correlation between AluS methylation and expression was only observed in ASD subgroup $\mathrm{M}$ and in sex- and age-matched controls in which the methylation pattern ${ }^{\mathrm{u}} \mathrm{C}^{\mathrm{m}} \mathrm{C}$ showed a moderate correlation with AluS expression. It is interesting to note that the methylation pattern ${ }^{\mathrm{u}} \mathrm{C}^{\mathrm{m}} \mathrm{C}$ was also significantly increased in subgroup $\mathrm{M}$ in the COBRA analysis. These findings suggest that AluS expression may be regulated by the AluS methylation pattern ${ }^{\mathrm{u}} \mathrm{C}^{\mathrm{m}} \mathrm{C}$. However, such relationships were not found when all ASD individuals were combined or in other ASD subgroups. In ASD subgroup $\mathrm{S}$, the AluS methylation patterns and

Table 7 Quantitative RT-PCR analyses of AluS expression levels in the LCLS of ASD and control groups

\begin{tabular}{llll}
\hline Group & Fold change (FC) & $\log _{2}(\mathrm{FC})$ & $P$ value \\
\hline ASD vs. control & 1.75 & 0.81 & 0.316 \\
Subgroup M vs. control & 1.05 & 0.06 & 0.953 \\
Subgroup L vs. control & 0.29 & -1.77 & 0.032 \\
Subgroup S vs. control & 3.68 & 1.88 & 0.038
\end{tabular}

The levels of Alu transcripts were normalized to the housekeeping gene $G A P D H$. The AluS expression levels were calculated using the $2^{-\Delta \Delta C t}$ method, and differences with a $P$ value $<0.05$, as determined by two-tailed $t$ tests with Benjamini-Hochberg correction, were considered significant expression levels were not correlated, although the AluS methylation pattern ${ }^{\mathrm{m}} \mathrm{C}^{\mathrm{u}} \mathrm{C}$ was significantly reduced, and AluS expression was over-expressed. Moreover, ASD subgroup L showed a significant reduction in AluS expression, but not DNA methylation, indicating that the decrease in AluS expression in ASD subgroup L might result from other epigenetic or gene regulatory mechanisms, such as the disrupted transcription of genes containing an Alu element by altered transcription factor binding at the promoter of the genes but not at the Alu promoter or the other gene regulatory mechanism that have been implicated in LCLs of ASD individuals [55]. These findings suggest that the AluS regulatory mechanism related to methylation might be unique for a specific ASD subpopulation, and there might be other regulatory mechanisms involved in the regulation of AluS methylation and expression, which should be investigated in future research.

The changes of Alu RNAs in LCLs from some ASD subgroups might reflect molecular function because Alu RNAs are involved in transcriptome diversity by contributing recognition sites for RNA editing and alternative splicing within Alu sequences [56]. Altered DNA methylation within Alu elements may have a negative impact on gene regulatory networks, which 

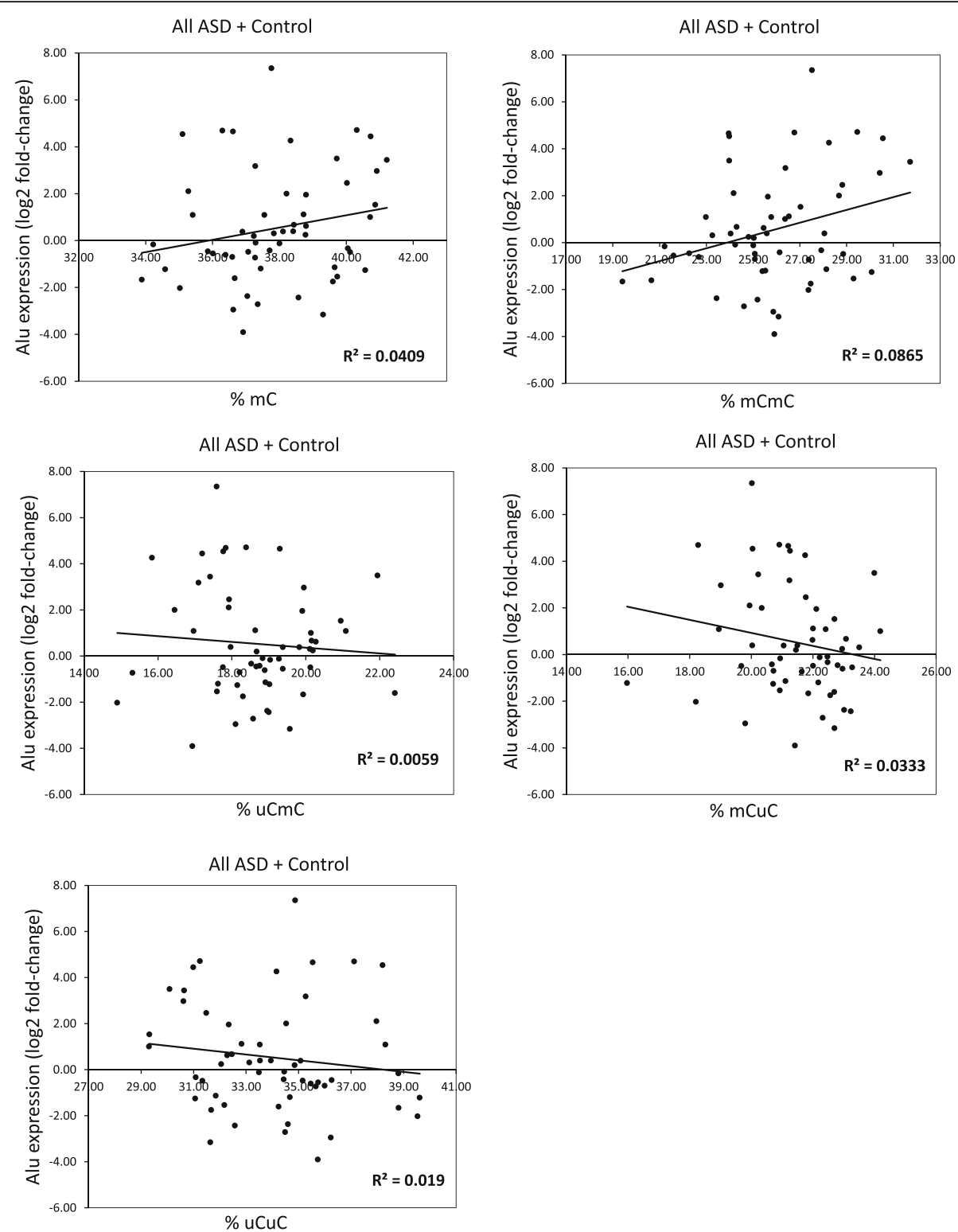

Fig. 6 Correlation analysis between AluS methylation and expression level for all LCL samples. The AluS expression for each $L C L$ was normalized with the average GAPDH dCt of the control group. The Alu expression levels were then calculated using the $2^{-\Delta \Delta C t}$ method

in turn, may affect the biological functions associated with ASD (Fig. 8). The exact mechanisms remain unclear, but it is possible that altered methylation within the Alu promoter, together with other gene regulatory mechanisms, may lead to changes in Alu transcript expression and retrotransposition. Because Alu elements contain transcription factor binding sites within their sequences, these elements could disrupt gene structure and functions by serving as an alternative transcription start site, enhancer, or promoter for cis-/trans-regulation of the target genes once inserted into a new genomic location by the retrotransposition $[28,29,57-59]$.
We obtained transcriptomic data from five different studies that used different sample types (e.g., whole blood, leukocytes, and LCLs) as well as different cohorts of subjects with ASD. It remains unclear whether ASD gene expression or methylation signatures will be similar across tissue sources. There might be variations in gene expression and methylation patterns among different sample types and among different cells in the same tissue type. This issue is a potential limitation of this study and should be investigated further in future research. In addition, some of the five selected transcriptome studies did not subgroup ASD individuals before performing DEG analysis and there were no ADI-R scores available 

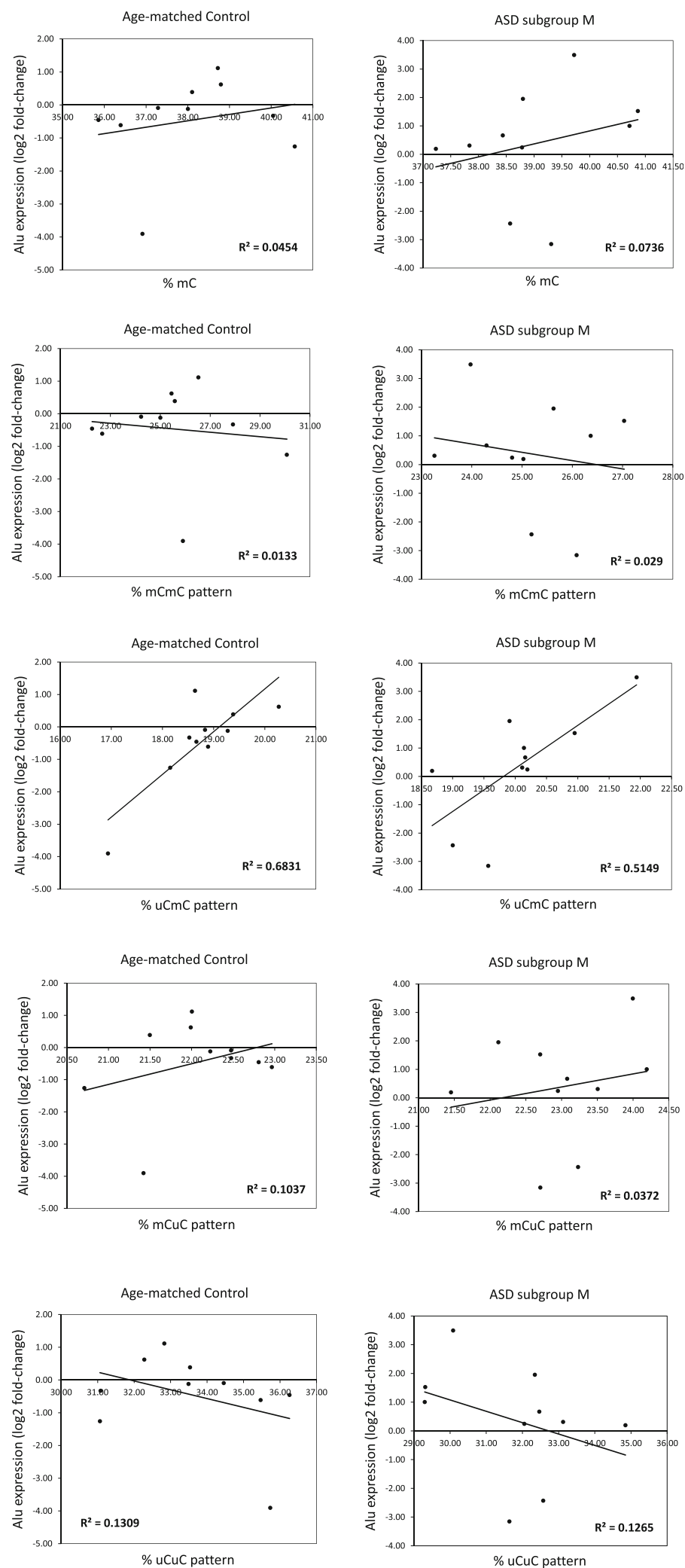

Fig. 7 Correlation analysis between AluS methylation and expression levels in ASD subgroup M and sex- and age-matched controls. The AluS expression of each $\mathrm{LCL}$ was normalized to the average GAPDH dCt of the control group. The Alu expression levels were then calculated using the $2^{-\Delta \Delta \mathrm{Ct}}$ method 


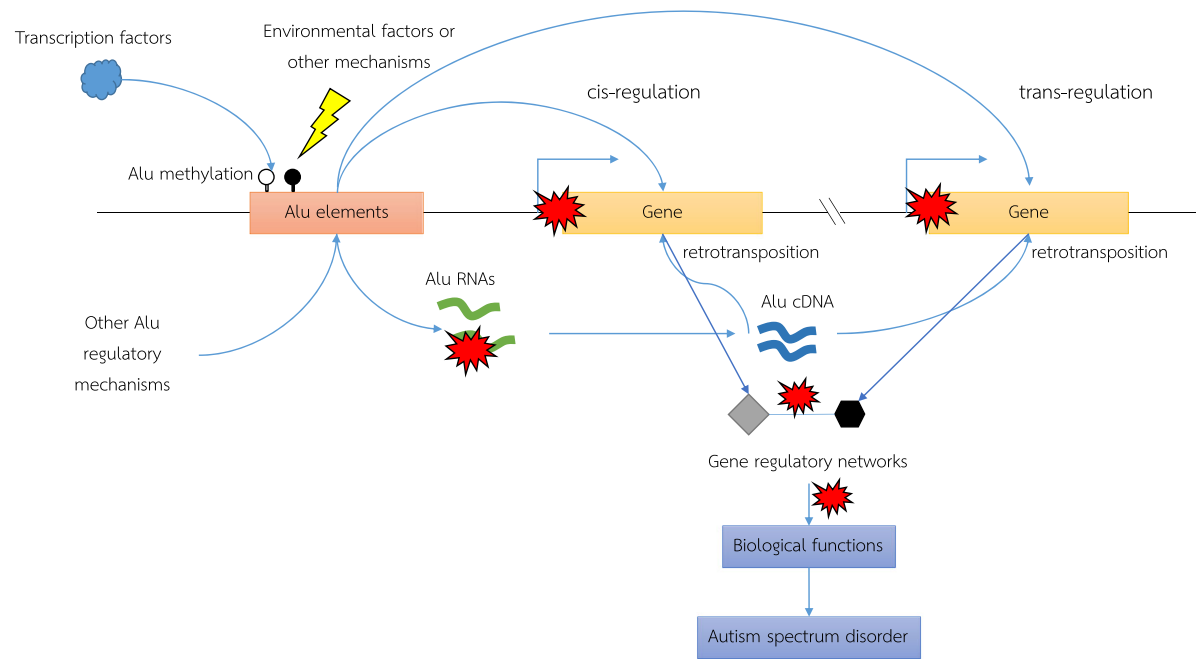

Fig. 8 Schematic diagram illustrating a possible mechanism of Alu elements in ASD. Our model suggests that exposure to environmental factors or dysregulation of other DNA methylation regulatory mechanisms lead to changes in CpG methylation patterns in Alu elements. Such changes alter transcription factor binding and, possibly in combination with other Alu regulatory mechanisms, cause the dysregulation of the expression and retrotransposition of Alu elements. Disrupted Alu retrotransposition results in changes in target genes via cis-/trans-regulatory mechanisms, which, in turn, dysregulate gene expression and gene regulatory networks known to be negatively impacted in ASD

for meta-analysis, whereas others used different criteria and strategies to divide ASD into subgroups. It is therefore difficult to relate our methylation analysis findings to previous analyses of Alu-inserted DEGs in which all ASD individuals were combined or studies using different subgrouping strategies. However, we performed Fisher's exact tests using the microarray data from a previous study (GSE15402) that used the same subgrouping criteria and the same cell model (LCLs) used in this study. Interestingly, we found that genes with Alu element insertion were associated with specific subgroups of ASD rather than with all individuals with ASD. The results of Alu methylation analysis using COBRA and Alu expression analysis using qRT-PCR also showed that the dysregulation of Alu methylation and Alu expression were observed only when ASD cases were divided into subgroups. This finding suggests that the subgrouping of ASD individuals will help reduce heterogeneity and may lead to the discovery of novel mechanisms associated with Alu element in ASD subpopulations. A better understanding of the molecular mechanisms specific for each ASD subgroup might allow the identification of biomarkers and treatment strategies personalized to each subgroup in the future. However, the sample size of this study is relatively small, especially when individuals with ASD were further divided into subgroups. The role of Alu in the context of ASD deserves further studies using a larger cohort. Most importantly, more experiments are needed to verify that Alu elements play important roles in ASD. Brain tissue samples may be used to confirm these findings, and single-cell RNA sequencing might help reduce cell heterogeneity.

\section{Conclusion}

Our findings show that the DEGs in males with ASD from several studies with different sample groups are associated with human Alu elements. Differentially expressed genes with Alu insertions were associated with neurodevelopmental disorders and neurological functions involved in the etiology of ASD. In particular, genes involved in estrogen receptor and androgen signaling pathways, which have been reported to be related with sex bias in ASD, were identified as DEGs with Alu insertions. In addition, the global methylation of AluS subfamilies in LCLs was investigated and revealed different AluS methylation patterns within specific ASD phenotypic subgroups. Our findings suggest that the classification of ASD patients into subgroups based on the clinical or behavioral phenotypes of individual patients might help improve our understanding of ASD etiology by reducing the inherent heterogeneity within the ASD population. In addition, this study provides suggestive evidence for an association between Alu elements and ASD.

\section{Additional files}

Additional file 1: Demographic information of LCLs used in this study (DOC $73 \mathrm{~kb}$ )

Additional file 2: Association analysis between the DEGs in ASD from GSE15402 and the human Alu-inserted genes lists when ASD individuals were sub-grouped based on ADI-R scores. The comparisons were performed for five types of Alu insertions, including exonized, exonic, intronic, promoter and all types. The Fisher's exact test $P$ value and number of DEGs are shown. (DOC 46 kb)

Additional file 3: List of the overlapping genes. (DOC $118 \mathrm{~kb}$ ) 
Additional file 4: Levels and patterns of Alu methylation in each individual. (DOC $98 \mathrm{~kb}$ )

Additional file 5: Correlation analysis between AluS methylation and expression level of ASD subgroup L. (PDF $329 \mathrm{~kb}$ )

Additional file 6: Correlation analysis between AluS methylation and expression level of ASD subgroup S. (PDF $333 \mathrm{~kb}$ )

\section{Abbreviations}

ADI-R: Autism Diagnostic Interview-Revised; ASD: Autism spectrum disorder; COBRA: Combined bisulfite restriction analysis; DEGs: Differentially expressed genes; DMRs: Differentially methylated regions; DMVs: Differentially methylated variants; DSM-5: The Diagnostic and Statistical Manual of Menta Disorders, Fifth Edition; ERK: Extracellular signal-regulated kinases; GEO: Gene Expression Omnibus; IPA: Ingenuity Pathway Analysis; LCLs: Lymphoblastoid cell lines; MAPK: Mitogen-activated protein kinases; RORA: Retinoic acid receptor-related orphan receptor alpha; RPMI: Roswell Park Memorial Institute; RT-PCR: Reverse transcription-polymerase chain reaction; SINEs: Short interspersed elements; TEs: Transposed elements; TRK: Tyrosine kinases

\section{Acknowledgements}

TSae, CT, and ST are graduate students in the M.Sc. Program in Clinical Biochemistry and Molecular Medicine, Faculty of Allied Health Sciences, Chulalongkorn University. This work is part of TSae's thesis research to be presented in partial fulfillment of the requirements for the M.Sc. degree. This research was supported by the Ratchadaphiseksomphot Endowment Fund part of the "Research Grant for New Scholar CU Researcher's Project" (GDNS 57-034-37-002) and the Faculty of Allied Health Sciences Research Fund (AHS-CU 58003) to TS. TSae, CT, and ST were financially supported by The 90th Anniversary Chulalongkorn University Fund (Ratchadaphiseksomphot Endowment Fund: TSae-GCUGR1125601055M 53-1; CTGCUGR1125601058M 53-4; ST-GCUGR1125601056M 53-2). TSae and ST received additional financial support from "The Scholarship from the Graduate School, Chulalongkorn University to commemorate the $72^{\text {nd }}$ anniversary of His Majesty King Bhumibala Aduladeja," while CT received the Research Assistant Scholarship, Chulalongkorn University. WH is supported by NIEHS grant R21 ES023061. AM is supported by the Thailand Research Fund (DPG5980005). KS is supported by the Thailand Research Fund (BRG5980001). We wish to thank Dr. Charoenchai Puttipanyalears for teaching TSae and $C T$ to conduct the COBRA. We also gratefully acknowledge the resources provided by the Autism Genetic Resource Exchange (AGRE) Consortium* and the participating AGRE families. The Autism Genetic Resource Exchange is a program of Autism Speaks and is supported, in part, by grant 1U24MH081810 from the National Institute of Mental Health to Clara M. Lajonchere (PI). *The AGRE Consortium: Dan Geschwind, M.D., Ph.D., UCLA, Los Angeles, CA; Maja Bucan, Ph.D., University of Pennsylvania, Philadelphia, PA; W.Ted Brown, M.D., Ph.D., F.A.C.M.G., N.Y.S. Institute for Basic Research in Developmental Disabilities, Long Island, NY; Rita M. Cantor, Ph.D., UCLA School of Medicine, Los Angeles, CA; John N. Constantino, M.D. Washington University School of Medicine, St. Louis, MO; T.Conrad Gilliam, Ph.D., University of Chicago, Chicago, IL; Martha Herbert, M.D., Ph.D., Harvard Medical School, Boston, MA; Clara Lajonchere, Ph.D, Cure Autism Now, Los Angeles, CA; David H. Ledbetter, Ph.D., Emory University, Atlanta, GA; Christa Lese-Martin, Ph.D., Emory University, Atlanta, GA; Janet Miller, J.D., Ph.D., Cure Autism Now, Los Angeles, CA; Stanley F. Nelson, M.D., UCLA School of Medicine, Los Angeles, CA; Gerard D. Schellenberg, Ph.D., University of Washington, Seattle, WA; Carol A. Samango-Sprouse, Ed.D., George Washington University, Washington, D.C.; Sarah Spence, M.D., Ph.D., UCLA, Los Angeles, CA; Matthew State, M.D., Ph.D., Yale University, New Haven, CT. Rudolph E. Tanzi, Ph.D., Massachusetts General Hospital, Boston, MA.

\section{Funding}

This research was supported by the Ratchadaphiseksomphot Endowment Fund part of the "Research Grant for New Scholar CU Researcher's Project" (GDNS 57-034-37-002) and the Faculty of Allied Health Sciences Research Fund (AHS-CU 58003) to TS. TSae, CT, and ST were financially supported by The 90th Anniversary Chulalongkorn University Fund (Ratchadaphiseksomphot Endowment Fund: TSae-GCUGR1125601055M 53-1: CT-GCUGR1125601058M 53-4; ST-GCUGR1 125601056M 53-2). TSae and ST received additional financial support from "The Scholarship from the Graduate School, Chulalongkorn University to commemorate the 72nd anniversary of His Majesty King Bhumibala Aduladeja," while CT received the Research Assistant Scholarship, Chulalongkorn University. WH is supported by NIEHS grant R21 ES023061. AM is supported by the Thailand
Research Fund (DPG5980005). KS is supported by the Thailand Research Fund (BRG5980001).

\section{Availability of data and materials}

The datasets generated and/or analyzed during the current study are available from the corresponding author on reasonable request.

\section{Authors' contributions}

TSae performed all the experiments, analyzed the data, and drafted the manuscript under the supervision of TS, AM, TT, WC, and KS. CT assisted TSae in performing COBRA and real-time RT-PCR experiments. ST conducted LCL culture and genomic DNA and RNA extraction. AM and TT provided the enzymes and reagents required for the COBRA analysis. WWH provided all LCLs and the Ingenuity Pathway Analysis program. TS conceived of the study, designed the experiments, and participated in the writing and editing of this manuscript. All the authors read and approved the final manuscript.

Ethics approval and consent to participate

Not applicable.

\section{Competing interests}

The authors declare that they have no competing interests.

\section{Publisher's Note}

Springer Nature remains neutral with regard to jurisdictional claims in published maps and institutional affiliations.

\section{Author details}

${ }^{1}$ M.Sc. Program in Clinical Biochemistry and Molecular Medicine, Department of Clinical Chemistry, Faculty of Allied Health Sciences, Chulalongkorn University, Bangkok, Thailand. ' Maximizing Thai Children's Developmenta Potential Research Unit, Department of Pediatrics, Faculty of Medicine, Chulalongkorn University and King Chulalongkorn Memorial Hospital, the Thai Red Cross Society, Bangkok, Thailand. ${ }^{3}$ Center of Excellence for Medical Genetics, Department of Pediatrics, Faculty of Medicine, Chulalongkorn University, Bangkok, Thailand. ${ }^{4}$ Excellence Center for Medical Genetics, King Chulalongkorn Memorial Hospital, Thai Red Cross Society, Bangkok, Thailand. ${ }^{5}$ Center of Excellence in Molecular Genetics of Cancer and Human Diseases, Department of Anatomy, Faculty of Medicine, Chulalongkorn University, Bangkok, Thailand. ${ }^{6}$ Age-related Inflammation and Degeneration Research Unit, Department of Clinical Chemistry, Faculty of Allied Health Sciences, Chulalongkorn University, 154 Soi Chula 12, Rama 1 Road, Wangmai, Pathumwan, Bangkok 10330, Thailand. ${ }^{7}$ Department of Biochemistry and Molecular Medicine, The George Washington University School of Medicine and Health Sciences, The George Washington University, Washington, DC, USA.

Received: 21 November 2017 Accepted: 3 April 2018 Published online: 16 April 2018

\section{References}

1. American Psychiatric Association: Diagnostic and Statistical Manual of Mental Disorders. 5th edition. Arlington, VA: 2013

2. Christensen DL, Baio J, Braun KV, Bilder D, Charles J, Constantino JN, Daniels $J$, Durkin MS, Fitzgerald RT, Kurzius-Spencer $M$, et al. Prevalence and characteristics of autism spectrum disorder among children aged 8 years-autism and developmental disabilities monitoring network, 11 sites, United States, 2012. Morbidity Mortal Weekl Repo Surveillance Summ (Washington, DC : 2002). 2016:65(3):1-23.

3. Lavelle TA, Weinstein MC, Newhouse JP, Munir K, Kuhlthau KA, Prosser LA. Economic burden of childhood autism spectrum disorders. Pediatrics. 2014 133(3):e520-9.

4. Schaefer GB, Mendelsohn NJ. Genetics evaluation for the etiologic diagnosis of autism spectrum disorders. Genet Med. 2008;10(1):4-12.

5. Moosa A, Shu H, Sarachana T, Hu WW. Are endocrine disrupting compounds environmental risk factors for autism spectrum disorder? Horm Behav. 2017. https://doi.org/10.1016/j.yhbeh.2017.10.003.

6. Tordjman S, Somogyi E, Coulon N, Kermarrec S, Cohen D, Bronsard G, Bonnot O, Weismann-Arcache C, Botbol M, Lauth B, et al. Gene x environment interactions in autism spectrum disorders: role of epigenetic mechanisms. Front Psychiatry. 2014;5:53. 
7. Bailey A, Le Couteur A, Gottesman I, Bolton P, Simonoff E, Yuzda E, Rutter M. Autism as a strongly genetic disorder: evidence from a British twin study. Psychol Med. 1995;25(1):63-77.

8. Hallmayer J, Cleveland S, Torres A, Phillips J, Cohen B, Torigoe T, Miller J, Fedele A, Collins J, Smith K, et al. Genetic heritability and shared environmental factors among twin pairs with autism. Arch Gen Psychiatry. 2011;68(11):1095-102.

9. Nguyen A, Rauch TA, Pfeifer GP, Hu WW. Global methylation profiling of lymphoblastoid cell lines reveals epigenetic contributions to autism spectrum disorders and a novel autism candidate gene, RORA, whose protein product is reduced in autistic brain. FASEB J. 2010;24(8):3036-51.

10. Wong CC, Meaburn EL, Ronald A, Price TS, Jeffries AR, Schalkwyk LC, Plomin R, Mill J. Methylomic analysis of monozygotic twins discordant for autism spectrum disorder and related behavioural traits. Mol Psychiatry. 2014;19(4):495-503.

11. Ginsberg MR, Rubin RA, Falcone $T$, Ting AH, Natowicz MR. Brain transcriptional and epigenetic associations with autism. PLoS One. 2012;7(9):e44736.

12. Ladd-Acosta C, Hansen KD, Briem E, Fallin MD, Kaufmann WE, Feinberg AP. Common DNA methylation alterations in multiple brain regions in autism. Mol Psychiatry. 2014;19(8):862-71.

13. Nardone S, Sams DS, Reuveni E, Getselter D, Oron O, Karpuj M, Elliott E. DNA methylation analysis of the autistic brain reveals multiple dysregulated biological pathways. Transl Psychiatry. 2014;4:e433.

14. Hu WW, Steinberg ME. Novel clustering of items from the Autism Diagnostic Interview-Revised to define phenotypes within autism spectrum disorders. Autism Res. 2009;2(2):67-77.

15. Hu WW, Sarachana T, Kim KS, Nguyen A, Kulkarni S, Steinberg ME, Luu T, Lai Y, Lee NH. Gene expression profiling differentiates autism case-controls and phenotypic variants of autism spectrum disorders: evidence for circadian rhythm dysfunction in severe autism. Autism Res. 2009;2(2):78-97.

16. Batzer MA, Deininger PL. Alu repeats and human genomic diversity. Nat Rev Genet. 2002;3(5):370-9.

17. Polak P, Domany E. Alu elements contain many binding sites for transcription factors and may play a role in regulation of developmental processes. BMC Genomics. 2006;7:133.

18. Luo Y, Lu X, Xie H. Dynamic Alu methylation during normal development, aging, and tumorigenesis. Biomed Res Int. 2014;2014:784706.

19. Baccarelli A, Bollati V. Epigenetics and environmental chemicals. Curr Opin Pediatr. 2009;21(2):243-51.

20. Patchsung $M$, Settayanon S, Pongpanich $M$, Mutirangura $D$, Jintarith $P$, Mutirangura A. Alu siRNA to increase Alu element methylation and prevent DNA damage. Epigenomics. 2018;10(2):175-85.

21. Barrett T, Troup DB, Wilhite SE, Ledoux P, Evangelista C, Kim IF, Tomashevsky M, Marshall KA, Phillippy KH, Sherman PM, et al. NCBI GEO archive for functional genomics data sets - 10 years on. Nucleic Acids Res. 2011;39(Database issue):D1005-10.

22. Edgar R, Domrachev M, Lash AE. Gene Expression Omnibus: NCBI gene expression and hybridization array data repository. Nucleic Acids Res. 2002;30(1):207-10

23. Levy A, Sela N, Ast G. TranspoGene and microTranspoGene: transposed elements influence on the transcriptome of seven vertebrates and invertebrates. Nucleic Acids Res. 2008;36(Database issue):D47-52.

24. Bao W, Kojima KK, Kohany O. Repbase update, a database of repetitive elements in eukaryotic genomes. Mob DNA. 2015;6:11.

25. Saeed Al, Sharov V, White J, Li J, Liang W, Bhagabati N, Braisted J, Klapa M, Currier T, Thiagarajan M, et al. TM4: a free, open-source system for microarray data management and analysis. BioTechniques. 2003;34(2):374-8.

26. Tiwawech D, Srisuttee R, Rattanatanyong P, Puttipanyalears C, Kitkumthorn $\mathrm{N}$, Mutirangura A. Alu methylation in serum from patients with nasopharyngeal carcinoma. Asian Pac J Cancer Prev. 2014;15(22):9797-800.

27. Mbarek O, Marouillat S, Martineau J, Barthelemy C, Muh JP, Andres C: Association study of the NF1 gene and autistic disorder. Am J Med Genet 1999, 88(6):729-732.

28. Elbarbary RA, Lucas BA, Maquat LE. Retrotransposons as regulators of gene expression. Science (New York, NY). 2016;351(6274):aac7247.

29. Ichiyanagi K. Epigenetic regulation of transcription and possible functions of mammalian short interspersed elements, SINEs. Genes Genet Syst. 2013;88(1):19-29.

30. Alter MD, Kharkar R, Ramsey KE, Craig DW, Melmed RD, Grebe TA, Bay RC, Ober-Reynolds S, Kirwan J, Jones JJ, et al. Autism and increased paternal age related changes in global levels of gene expression regulation. PLoS One. 2011;6(2):e16715.
31. Gregg JP, Lit L, Baron CA, Hertz-Picciotto I, Walker W, Davis RA, Croen LA, Ozonoff S, Hansen R, Pessah IN, et al. Gene expression changes in children with autism. Genomics. 2008;91(1):22-9.

32. Kong SW, Collins CD, Shimizu-Motohashi Y, Holm IA, Campbell MG, Lee IH, Brewster SJ, Hanson E, Harris HK, Lowe KR, et al. Characteristics and predictive value of blood transcriptome signature in males with autism spectrum disorders. PLoS One. 2012;7(12):e49475.

33. Pramparo T, Lombardo MV, Campbell K, Barnes CC, Marinero S, Solso S, Young J, Mayo M, Dale A, Ahrens-Barbeau C, et al. Cell cycle networks link gene expression dysregulation, mutation, and brain maldevelopment in autistic toddlers. Mol Syst Biol. 2015;11(12):841.

34. Tsirigos A, Rigoutsos I. Alu and b1 repeats have been selectively retained in the upstream and intronic regions of genes of specific functional classes. PLoS Comput Biol. 2009;5(12):e1000610

35. Baron-Cohen S, Auyeung B, Norgaard-Pedersen B, Hougaard DM, Abdallah MW, Melgaard L, Cohen AS, Chakrabarti B, Ruta L, Lombardo MV. Elevated fetal steroidogenic activity in autism. Mol Psychiatry. 2015;20(3):369-76.

36. Sarachana T, Hu WW. Differential recruitment of coregulators to the RORA promoter adds another layer of complexity to gene (dys) regulation by sex hormones in autism. Mol Autism. 2013;4(1):39.

37. Sarachana T, Xu M, Wu RC, Hu WW. Sex hormones in autism: androgens and estrogens differentially and reciprocally regulate RORA, a novel candidate gene for autism. PLoS One. 2011;6(2):e17116.

38. Knickmeyer R, Baron-Cohen S, Raggatt P, Taylor K, Hackett G. Fetal testosterone and empathy. Horm Behav. 2006;49(3):282-92.

39. Tordjman S, Ferrari P, Sulmont V, Duyme M, Roubertoux P. Androgenic activity in autism. Am J Psychiatry. 1997;154(11):1626-7.

40. Whitehouse AJ, Maybery MT, Hart R, Mattes E, Newnham JP, Sloboda DM, Stanley FJ, Hickey M. Fetal androgen exposure and pragmatic language ability of girls in middle childhood: implications for the extreme male-brain theory of autism. Psychoneuroendocrinology. 2010;35(8):1259-64.

41. Crider A, Thakkar R, Ahmed AO, Pillai A. Dysregulation of estrogen receptor beta (ERbeta), aromatase (CYP19A1), and ER co-activators in the middle frontal gyrus of autism spectrum disorder subjects. Mol Autism. 2014;5(1):46.

42. Altun $H$, Kurutas EB, Sahin N, Sinir H, Findikli E. Decreased levels of $G$ protein-coupled estrogen receptor in children with autism spectrum disorders. Psychiatry Res. 2017;257:67-71.

43. Hu WW, Nguyen A, Kim KS, Steinberg ME, Sarachana T, Scully MA, Soldin SJ, LuU T, Lee NH. Gene expression profiling of lymphoblasts from autistic and nonaffected sib pairs: altered pathways in neuronal development and steroid biosynthesis. PLoS One. 2009;4(6):e5775.

44. Hu WW, Sarachana T, Sherrard RM, Kocher KM. Investigation of sex differences in the expression of RORA and its transcriptional targets in the brain as a potential contributor to the sex bias in autism. Mol Autism. 2015;6:7.

45. Sarachana T, Hu WW. Genome-wide identification of transcriptional targets of RORA reveals direct regulation of multiple genes associated with autism spectrum disorder. Mol Autism. 2013;4(1):14

46. Correia CT, Coutinho AM, Sequeira AF, Sousa IG, Lourenco Venda L, Almeida JP, Abreu RL, Lobo C, Miguel TS, Conroy J, et al. Increased BDNF levels and NTRK2 gene association suggest a disruption of BDNF/TrkB signaling in autism. Genes Brain Behav. 2010;9(7):841-8.

47. Mukaetova-Ladinska EB, Arnold H, Jaros E, Perry R, Perry E. Depletion of MAP2 expression and laminar cytoarchitectonic changes in dorsolateral prefrontal cortex in adult autistic individuals. Neuropathol Appl Neurobiol. 2004;30(6):615-23.

48. Suda S, Iwata K, Shimmura C, Kameno Y, Anitha A, Thanseem I, Nakamura K, Matsuzaki H, Tsuchiya KJ, Sugihara G, et al. Decreased expression of axon-guidance receptors in the anterior cingulate cortex in autism. Mol Autism. 2011;2(1):14.

49. Ebert $\mathrm{DH}$, Greenberg ME. Activity-dependent neuronal signalling and autism spectrum disorder. Nature. 2013;493(7432):327-37.

50. Wei H, Zou H, Sheikh AM, Malik M, Dobkin C, Brown WT, Li X. IL-6 is increased in the cerebellum of autistic brain and alters neural cell adhesion, migration and synaptic formation. J Neuroinflammation. 2011:8:52.

51. El-Ansary A, Al-Ayadhi L. Neuroinflammation in autism spectrum disorders. J Neuroinflammation. 2012;9:265

52. Liu WM, Maraia RJ, Rubin CM, Schmid CW. Alu transcripts: cytoplasmic localisation and regulation by DNA methylation. Nucleic Acids Res. 1994; 22(6):1087-95.

53. Xing J, Hedges DJ, Han K, Wang H, Cordaux R, Batzer MA. Alu element mutation spectra: molecular clocks and the effect of DNA methylation. J Mol Biol. 2004;344(3):675-82 
54. Kochanek S, Renz D, Doerfler W. Transcriptional silencing of human Alu sequences and inhibition of protein binding in the box $\mathrm{B}$ regulatory elements by 5'-CG-3' methylation. FEBS Lett. 1995;360(2):115-20.

55. Sarachana T, Zhou R, Chen G, Manji HK, Hu WW. Investigation of posttranscriptional gene regulatory networks associated with autism spectrum disorders by microRNA expression profiling of lymphoblastoid cell lines. Genome Med. 2010;2(4):23.

56. Sorek R, Ast G, Graur D. Alu-containing exons are alternatively spliced. Genome Res. 2002;12(7):1060-7.

57. Deininger P. Alu elements: know the SINEs. Genome Biol. 2011;12(12):236.

58. Deininger PL, Batzer MA. Alu repeats and human disease. Mol Genet Metab. 1999;67(3):183-93.

59. Hasler J, Strub K. Alu elements as regulators of gene expression. Nucleic Acids Res. 2006;34(19):5491-7.

Ready to submit your research? Choose BMC and benefit from:

- fast, convenient online submission

- thorough peer review by experienced researchers in your field

- rapid publication on acceptance

- support for research data, including large and complex data types

- gold Open Access which fosters wider collaboration and increased citations

- maximum visibility for your research: over $100 \mathrm{M}$ website views per year

At BMC, research is always in progress.

Learn more biomedcentral.com/submissions 